\title{
Coordinated ground-based, low altitude satellite and Cluster observations on global and local scales during a transient post-noon sector excursion of the magnetospheric cusp
}

H. J. Opgenoorth ${ }^{1,7}$ M. Lockwood ${ }^{2}$ D. Alcaydé ${ }^{3}$ E. Donovan ${ }^{4}$ M. J. Engebretson ${ }^{5}$ A. P. van Eyken ${ }^{6}$, K. Kauristie $^{7}$ M. Lester ${ }^{8}$, J. Moen ${ }^{9}$, J. Waterman ${ }^{10}$, H. Alleyne ${ }^{11}$, M. André ${ }^{1}$, M. W. Dunlop ${ }^{12}$, N. Cornilleau-Wehrlin ${ }^{13}$, A. Masson $^{14}$, A. Fazerkerley ${ }^{15}$, H. Rème ${ }^{3}$, R. André ${ }^{14}$, O. Amm ${ }^{7}$, A. Balogh ${ }^{12}$, R. Behlke ${ }^{1}$, P. L. Blelly ${ }^{3}$, H. Boholm ${ }^{6}$, E. Borälv ${ }^{1}$, J. M. Bosqued ${ }^{3}$, S. Buchert ${ }^{1}$, M. Candidi ${ }^{21}$, J. C. Cerisier ${ }^{16}$, C. Cully ${ }^{1,4}$, W. F. Denig ${ }^{26}$, P. Eglitis ${ }^{1}$, R. A. Greenwald ${ }^{17}$, B. Jackal ${ }^{4}$, J. D. Kelly ${ }^{18}$, I. Krauklis ${ }^{15}$, G. Lu ${ }^{19}$, I. R. Mann ${ }^{20}$, M. F. Marcucci ${ }^{21}$, I. W. McCrea ${ }^{2}$, M. Maksimovic ${ }^{13}$, S. Massetti ${ }^{21}$, P. M. E. Décréau ${ }^{27}$, D. K. Milling ${ }^{20}$, S. Orsini ${ }^{21}$, F. Pitout ${ }^{1,3}$, G. Provan ${ }^{8}$, J. M. Ruohoniemi ${ }^{17}$, J. C. Samson ${ }^{22}$, J. J. Schott ${ }^{23}$, F. Sedgemore-Schulthess ${ }^{24}$, R. Stamper ${ }^{2}$, P. Stauning ${ }^{10}$, A. Strömme ${ }^{25}$, M. Taylor ${ }^{15}$, A. Vaivads ${ }^{1}$, J. P. Villain ${ }^{14}$, I. Voronkov ${ }^{22}$, J. A. Wild ${ }^{8}$, and M. Wild ${ }^{2}$

${ }^{1}$ Swedish Institute of Space Physics, S-75121 Uppsala, Sweden

${ }^{2}$ Rutherford Appleton Lab., Dept. Space Sci., Didcot OX11 0QX, Oxon, UK

${ }^{3}$ CNRS, CESR, F-31028 Toulouse 04, France

${ }^{4}$ Univ. Calgary, Dept. Phys. \& Astron., Calgary, AB T2N 1N4, Canada

${ }^{5}$ Augsburg Coll., Dept. Phys., Minneapolis, MN 55454 USA

${ }^{6}$ EISCAT Scientific Assoc., N-9171 Longyearbyen, Norway

${ }^{7}$ Finnish Meteorological Institute, FIN-00101 Helsinki, Finland

${ }^{8}$ University of Leicester, Dept. Phys. and Astron., Leicester LE1 7RH, UK

${ }^{9}$ University of Oslo, Dept. Phys., POB 1048, N-0316 Oslo, Norway

${ }^{10}$ Danish Meteorol. Inst., Lyngbyvej 100, DK-2100 Copenhagen, Denmark

${ }^{12}$ University of Sheffield, Sheffield S1 3JD, S Yorkshire, UK

${ }^{12}$ Imperial College, Blackett Lab., London SW7 2BZ, UK

${ }^{13}$ CETP, Centre Etud. Env. Terr. \& Planetaires, F-78140 Velizy, France

${ }^{14}$ Space Science Division, ESTEC, Noordwijk, The Netherlands

${ }^{15}$ Univ. College, Mullard Space Sci. Lab., Dorking RH5 6NT, Surrey, UK

${ }^{16}$ CETP, F-94107 St. Maur, France

${ }^{17}$ Johns Hopkins Univ., Appl. Phys. Lab., Laurel, MD 20723, USA

${ }^{18}$ SRI International, Menlo Park, CA 94025 USA

${ }^{19}$ Natl. Ctr. Atmosph. Res., High Alt. Observ., Boulder, CO 80307, USA

${ }^{20}$ York University, Dept. Phys., York Y01 5DD, N Yorkshire, UK

${ }^{21}$ CNR, IFSI, Via Fosso Cavaliere 100, I-00133 Rome, Italy

${ }^{22}$ Univ. of Alberta, Dept. Phys., Edmonton, AB T6G 2J1, Canada

${ }^{23}$ EOST, Ecole \& Observ. Sci. Terre, F-67084 Strasbourg, France

${ }^{24}$ DSRI, Danish Space Res. Inst., DK-2100 Copenhagen O, Denmark

${ }^{25}$ University of Troms $\varnothing$, Dept. Phys., Troms $\varnothing$, Norway

${ }^{26}$ AFRL, Boston, USA

${ }^{27}$ CNRS, Lab. Phys. \& Chim. Environm., F-45071 Orleans, France

Received: 23 April 2001 - Revised: 10 July 2001 - Accepted: 16 July 2001

\begin{abstract}
On 14 January 2001, the four Cluster spacecraft passed through the northern magnetospheric mantle in close conjunction to the EISCAT Svalbard Radar (ESR) and approached the post-noon dayside magnetopause over Greenland between 13:00 and 14:00 UT. During that interval, a
\end{abstract}

Correspondence to: H. J. Opgenoorth (opg@irfu.se) sudden reorganisation of the high-latitude dayside convection pattern accurred after 13:20 UT, most likely caused by a direction change of the Solar wind magnetic field. The result was an eastward and poleward directed flow-channel, as monitored by the SuperDARN radar network and also by arrays of ground-based magnetometers in Canada, Greenland and Scandinavia. After an initial eastward and later 
poleward expansion of the flow-channel between 13:20 and 13:40 UT, the four Cluster spacecraft, and the field line footprints covered by the eastward looking scan cycle of the Söndre Strömfjord incoherent scatter radar were engulfed by cusp-like precipitation with transient magnetic and electric field signatures. In addition, the EISCAT Svalbard Radar detected strong transient effects of the convection reorganisation, a poleward moving precipitation, and a fast ion flowchannel in association with the auroral structures that suddenly formed to the west and north of the radar. From a detailed analysis of the coordinated Cluster and ground-based data, it was found that this extraordinary transient convection pattern, indeed, had moved the cusp precipitation from its former pre-noon position into the late post-noon sector, allowing for the first and quite unexpected encounter of the cusp by the Cluster spacecraft. Our findings illustrate the large amplitude of cusp dynamics even in response to moderate solar wind forcing. The global ground-based data proves to be an invaluable tool to monitor the dynamics and width of the affected magnetospheric regions.

Key words. Magnetospheric cusp, ionosphere, reconnection, convection flow-channel, Cluster, ground-based observations

\section{Introduction}

The term "cusp" is today applied to a number of characteristics of the dayside magnetosphere: in particular, the magnetic cusp, the particle cusp, the cusp aurora and the cusp currents. The concept that we now term the magnetic cusp is as old as the concept that we now term the magnetosphere. Both first appeared in the paper by Chapman and Ferraro (1931). For a model planar magnetopause, they defined two magnetic null points on the magnetopause around which the magnetopause surface currents circle ( $J_{C F}$ - "Chapman-Ferraro" current). These are connected by field lines, that Chapman and Ferraro termed "Horns", to a single point in the dayside auroral ionosphere. For a generalised magnetopause shape, the cusp remains as a topological boundary around noon that separates field lines passing through the dayside magnetosphere from those extending anti-sunward into the tail lobe. For a given notional electric field imposed on the magnetosphere by the solar wind flow ( $\boldsymbol{E}_{S W}$ from dawn to dusk for purely southward IMF), the cusp can be regarded as the location where $\left(\boldsymbol{J}_{C F} \cdot \boldsymbol{E}_{S W}\right)$ reverses from positive to negative. Thus, sunward of the magnetic cusp, energy goes from the field to the particles $\left(\boldsymbol{J}_{C F} \cdot \boldsymbol{E}_{S W}>0\right)$, whereas anti-sunward of the cusp energy goes from the particles to the fields $\left(\boldsymbol{J}_{C F} \cdot \boldsymbol{E}_{S W}<0\right)$ (Cowley, 1991).

The discovery of magnetosheath-like plasma precipitating inside the magnetosphere (Heikkila and Winningham, 1971; Frank, 1971) was initially interpreted in terms of particle entry at the null points of the magnetic cusp in a closed magnetosphere; hence, the particle signature itself was also given the name cusp. However, transfer of plasma into a null point is not an adequate explanation since a breakdown of the "frozen-in field" condition is still required in order to provide transfer onto magnetospheric field lines. It was soon realised that magnetosheath plasma actually precipitated over a broad local time sector on the dayside (Formisano et al., 1980), and so the additional concept of the "cleft", which maps to a closed LLBL field line torus containing sheath plasma, was introduced by Heikkila (1972). Although this conceptual difference was introduced as early as 1972, a quantitative difference between the cusp and the cleft was not defined until the work of Newell and Meng (1988). Various mechanisms for populating a closed LLBL with sheath plasma have been proposed, while others have argued that there is no need to invoke a closed LLBL at all. It appears that all the features of the LLBL can be interpreted in terms of open field lines that have either been reconnected only very recently (alternatively have been re-closed), or which thread the magnetopause away from the subsolar point where magnetosheath number densities are lower (Lockwood and Smith, 1993; Fuselier et al., 1999). This latter concept can indeed explain a number of long-standing anomalies in the magnetosphere (Lockwood, 1997a).

There is widespread agreement with the concept that the particle cusp is where the shocked solar wind plasma of the magnetosheath has the most direct entry into the magnetosphere (Newell and Meng, 1988; 1992). Thus, irrespective of the mechanism invoked which gives rise to that entry, it is agreed that the cusp is where injected sheath plasma has characteristics, in terms of the concentration and temperature of the ion and electron gases, that are most similar to the corresponding values in the external magnetosheath. There is less agreement as to what this means in terms of the quantitative identification of the cusp. One difficulty is that the magnetosheath conditions vary both temporally (in response to the wide range of variations in the upstream solar wind) and spatially (primarily with distance from the nose of the magnetosphere) (Spreiter et al., 1966). Given that, for example, hourly averages of the upstream solar wind number density can vary from almost zero to $85 \times 10^{6} \mathrm{~m}^{3}$ (with a mode value of $3 \times 10^{6} \mathrm{~m}^{3}$ ) (Hapgood et al., 1991); such a temporal variation must imply that any quantitative criteria used to define the cusp should have threshold values that depend on the upstream solar wind conditions in an appropriate manner. The spatial variation of the sheath plasma introduces the complication that quantitative comparison with the cusp depends on which location in the magnetosheath is considered most relevant - a judgement which depends on the adopted model of the plasma injection.

In a closed magnetosphere, the entire magnetopause maps to the ionosphere only at the singular points envisaged by Chapman and Ferraro. The addition of open flux threading the magnetopause means that this point is enlarged into a non-zero region (Crooker et al., 1991). In the open magnetosphere, a boundary-normal field is added to those parts of the magnetopause where the newly-opened field lines evolve away from a reconnection site. We can make a simple estimate of the area of the cusp for an open magnetosphere 
using an average transpolar voltage of $50 \mathrm{kV}$ generated by reconnection. Such reconnection can commence somewhere in a fully-closed magnetopause. Since the ionospheric field is roughly constant at $5 \times 10^{-5} \mathrm{~T}$, the area of the cusp in the ionosphere grows at a rate of $5 \times 10^{4} /\left(5 \times 10^{-5}\right)=$ $10^{9} \mathrm{~m}^{2} \mathrm{~s}^{-1}$. This growth would continue for about $10 \mathrm{~min}$, after which the field lines would no longer be classified as cusp (because they thread the tail rather than the dayside magnetopause, and also because the precipitation in the ionosphere would be classified as mantle or polar cap rather than cusp (Lockwood and Davis, 1995). By this time, the area of the ionospheric cusp has grown from zero to $6 \times 10^{5} \mathrm{~km}^{2}$. Given that the peak cusp width is observed to be roughly at $5^{\circ}$ of latitude (about $600 \mathrm{~km}$ ) (Newell et al., 1989), this means that the longitudinal extent has grown to about $1000 \mathrm{~km}$ (corresponding to about $2.5 \mathrm{~h}$ of Magnetic Local Time). The definition of the cusp employed in some statistical surveys results in smaller estimates of the cusp extent, but the above is consistent with the results from several surveys of magnetosheath plasma in the magnetosphere (e.g. Newell et al., 1989; Newell and Meng, 1992; Stubbs et al., 2001).

A key characteristic often displayed by magnetosheath plasma precipitating in the cusp is the dispersion of the ions in energy, mass, and pitch angle. The ions are dispersed according to their field parallel time-of-flight in the "velocity filter effect" (Rosenbauer et al., 1975; Reiff et al., 1977). This effect means that ions injected from one point on the magnetopause are dispersed in the convective flow on their path of precipitation along the magnetic field. During periods of southward IMF and anti-sunward convection, the latitudeenergy dispersion is reversed in direction compared to periods of northward IMF with sunward convection (Burch et al., 1982, 1985; Woch and Lundin, 1992). However, the cusp ions detected also display a range of ion energies and pitch angles at any one observation point and this reveals that the magnetopause source must be an extended region (of the order of $10 R_{E}$ ) along the flow streamlines of newly-opened field lines (Lockwood and Smith, 1993). Reconnection provides a unique explanation of this extended source region since once a field line is opened, the plasma streams continuously across the boundary. Onsager et al. (1993) demonstrated this principle by modelling ions injected onto newlyopened field lines but since they employed a low steady-state average convection electric field, they did not predict as great an extent of the source region for the cusp particles as in the time-dependent model of Lockwood (1995; 1997b). The ions observed are first accelerated as they cross the magnetopause (for an open magnetosphere, this is the Alfvén wave that is launched by the reconnection site into the inflow from the magnetosheath side of the boundary; Vasyliunas, 1995) at locations between the reconnection site and the magnetic cusp (where $\boldsymbol{J}_{C F} \cdot \boldsymbol{E}_{S W}>0$ ) (Hill and Reiff, 1977; Cowley, 1981), but they are then decelerated poleward of the magnetic cusp (where $\boldsymbol{J}_{C F} \cdot \boldsymbol{E}_{S W}>0$ ) (Lockwood, 1995). Ions are also accelerated by passing through the other Alfvén wave that was launched by the reconnection site into the inflow from the magnetospheric side of the boundary (Lockwood, 1997a, b) and by other similarly-produced Alfvénic disturbances, such as slow-mode shocks and expansion fans (Lockwood and Hapgood, 1998). Other ions will be accelerated above solar wind energies at the bow shock (Fuselier et al., 1999), where $\boldsymbol{J}_{B S} \cdot \boldsymbol{E}_{S W}>0$ (Cowley, 1991).

The reconnection theory of the cusp predicts that at the dayside magnetopause, magnetosheath plasma will be seen within a layer on northward-pointing newly-opened field lines. Here, we refer to this layer as the "exterior" cusp, and it is sometimes also called the "entry layer" or "frontside boundary layer" (Haerendel et al., 1978) or the (open) LLBL (Paschmann et al., 1986). The plasma in the exterior cusp will be recognisably different from the magnetosheath proper. First, the accelerated ions discussed above will be present (but note that these are also found in the magnetosheath boundary layer formed by the open field lines outside the magnetopause). Second, the plasma concentration will be roughly half the sheath value at the point of entry because roughly half the sheath plasma is transmitted and half is reflected at the magnetopause (Cowley, 1982; Fuselier et al., 1991). Third, the ion velocity distributions will be ordered by the magnetic field direction instead of by the magnetosheath flow.

Cusp plasma is also seen on the southward-pointing field lines of the "interior" cusp along which the plasma precipitates into the ionosphere. It is also seen on the field lines that point anti-sunward/sunward with small $B_{Z}$ in the northern/southern hemisphere, connecting the open LLBL with the magnetic cusp. The reconnection theory of the cusp is unique in predicting that the ion precipitation can be continuously dispersed across the regions classed as "(open) LLBL", "cusp", "mantle" and "polar cap" as the field lines evolve from the reconnection site into the tail lobe (Lockwood, 1997b). Most field lines will evolve anti-sunward close to the magnetic cusp. Spatial and temporal structure in the reconnection means that this continuous dispersion will not always be observed, but the fact that it is observed when the reconnection is relatively steady and constant (Onsager et al., 1993; Lockwood et al., 1994) is highly significant.

For the most recently-opened field lines, electrons, like ions, can also show time-of-flight velocity dispersion effects (Burch et al., 1982; Gosling et al., 1990b). After a field line is opened, the first effect is the loss of the magnetospheric electrons: field-parallel and higher energy electrons are lost first. The second effect is the arrival of some lower-energy magnetosheath electrons. However, the full flux of sheath electrons does not arrive until the magnetosheath ions arrive. In general, the number density of electrons in the cusp is always very close to that of the ions (Burch, 1985; Lockwood and Hapgood, 1998). How this "quasi-neutrality" is maintained on newly-opened field lines as they evolve is one of the main current problems in understanding the cusp.

The magnetosheath electrons and ions which precipitate into the cusp/cleft ionosphere generate a characteristic aurora. The relatively low energies of these particles result in an aurora dominated by high altitude 630.0 and $636.4 \mathrm{~nm}$ (red line) emissions of atomic oxygen, with much lower intensi- 

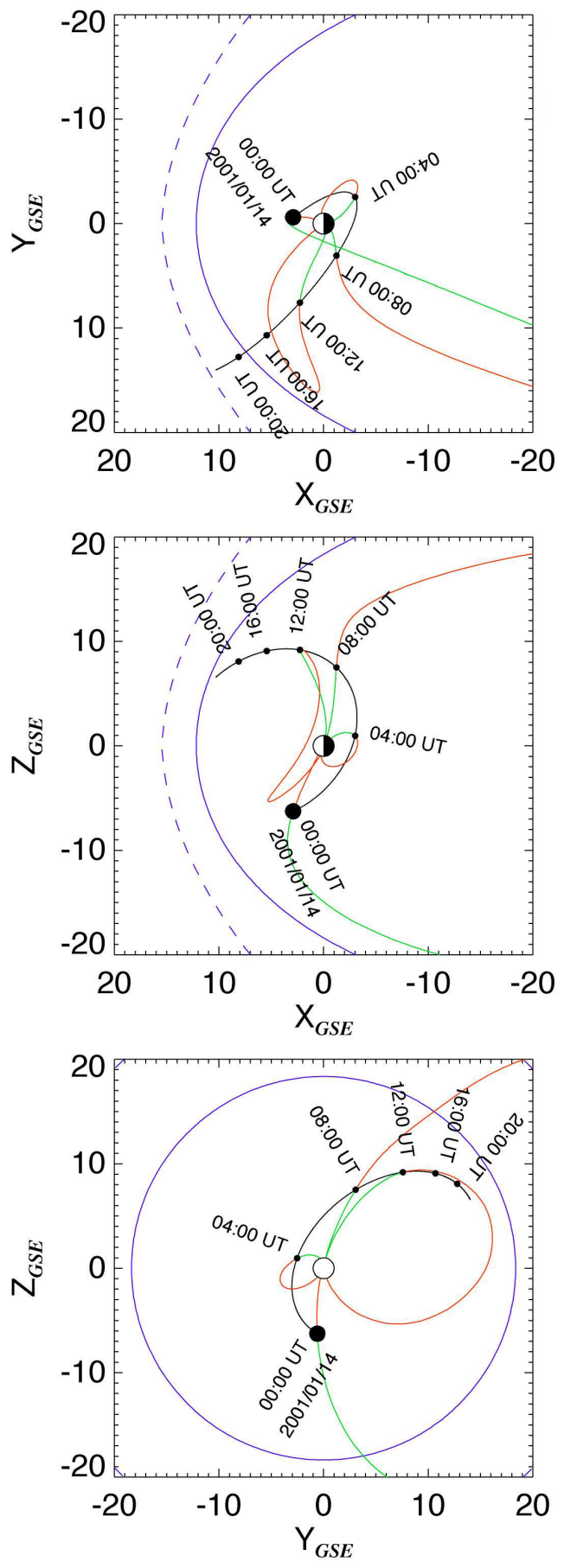

Fig. 1. Plot of a part of the Cluster orbit on 14 January 2001, in a model of the magnetosphere (Tsyganenko-96, see text for chosen input parameters) projected onto the GSE $X Y-, X Z$ - and $Y Z$ planes (i.e. from top to bottom seen from the top, east and front of the magnetosphere). The UT times for the momentary location of Cluster are indicated every $4 \mathrm{~h}$, starting in the southern hemisphere, through perigee and towards the final exit from the magnetopause in the northern hemisphere. The full blue line represents the model magnetopause, the broken blue line in the top two panels the model bow-shock, and the green and red lines are field lines connecting Cluster to the northern and southern hemisphere, respectively. ties of the $557.7 \mathrm{~nm}$ (green line) emissions. This is due to the fact that the ${ }^{1} D_{2}$ electron state is readily excited $(1.96 \mathrm{eV}$ above the ${ }^{3} P$ doublet ground state), whereas very few atoms are excited to the ${ }^{1} S_{0}\left(4.17 \mathrm{eV}\right.$ above the $\left.{ }^{3} P\right)$. The excitation can be largely caused by the elevation of the ionospheric electron temperature such that the electrons on the hot tail of the thermal ionospheric gas are very efficient in exciting the ${ }^{1} D_{2}$ state (Wickwar and Kofman, 1984; Lockwood et al., 1993a; Davis and Lockwood, 1996). A region of dominant red-line emission was first reported by Sandford (1964). This was shown to be poleward of the more energetic dayside auroral precipitation by Eather and Mende (1971). The association with the newly-discovered cusp precipitation was made by Heikkila (1972). This red-line aurora either contains or consists of a series of poleward-moving events when the IMF is southward (e.g. Sandholt et al., 1985; 1992).

The electron heating in the cusp region which was invoked above as a major cause of the cusp/cleft aurora was inferred in a statistical survey of the topside ionosphere by Titheridge (1976) and has been directly observed by satellite (Brace et al., 1982; Curtis et al., 1982) and incoherent scatter radar (Wickwar and Kofman, 1984; Watermann et al., 1994; McCrea et al., 2000). With very high time resolution (10 s) measurements, Lockwood et al. (1993b) have reported that the cusp electron temperature enhancements can sometimes consist of a series of poleward-moving events, very similar to the behaviour of the red-line auroral transients.

The direction of the curvature force on newly-opened field lines depends on the IMF $B_{Y}$ component, and this gives the longitudinal motion of newly-opened field lines that is observed at the magnetopause (Gosling et al., 1990a) and in the ionosphere (Cowley, 1981; Greenwald et al., 1990). The polarity of the electric fields and Hall, Pedersen and field-aligned currents that are associated with this SvalgaardMansurov effect depend on the $B_{Y}$ component and on the hemisphere considered. The term "cusp" is sometimes applied to the $B_{Y}$-dependent field-aligned currents which bring the east-west flows to the ionosphere (Taguchi et al., 1993). Other authors have preferred the title of "mantle" currents since they are sometimes found in the precipitation region termed mantle, rather than in the cusp precipitation region. This debate is best understood in terms of the evolution of the newly-opened field lines; the precipitation evolves from cusp to mantle classifications roughly $12 \mathrm{~min}$ after reconnection. This is also roughly the time scale for a field line to straighten. As the field-aligned currents on newly-opened field lines are associated with this unbending (Saunders, 1989; Mei et al., 1995), we should expect them to be close to the cusp/mantle boundary, but they can be in either region in any one case. The pattern of field-aligned currents for nonzero IMF $B_{Y}$ was proposed by Cowley et al. (1991b) from considerations about how newly-opened field lines evolve. These predictions of where the particle precipitations of various classifications will be seen relative to the field-aligned currents are consistent with the observations by de la Beaujardiere et al. (1993).

A major debate exists as to how much the cusp repre- 
sents a stable, ever-present structure and how much can it vary in response to spatial and temporal variations in the reconnection rate (see review by Smith and Lockwood, 1996). Lockwood and Smith (1992) were the first to suggest that the cusp was made up of newly-opened field lines produced by successive reconnection pulses, thereby making the cusp the signature of a series of "flux transfer events" (Cowley et al., 1991a). Their work was inspired by the fact that ionospheric signatures of the cusp appeared in various different sets of meridional ground-based data as a series of polewardmoving events, whereas satellite data were often interpreted in terms of a spatial structure (note that the latter is even implied by the term cusp itself). The time-dependent reconnection model of the particle cusp can reproduce the structure seen in cusp ions at low altitudes (Escoubet et al., 1992; Lockwood and Davis, 1996) at middle altitudes (Lockwood et al., 1998) and at the magnetopause in flux transfer events themselves (Lockwood and Hapgood, 1998).

For clear southward IMF conditions, such consecutive poleward moving transients are readily identified in various sets of meridional ground-based data, for example, magnetometers (Stauning, 1995; Stauning et al., 1994; Clauer et al., 1995; Pilipenko et al., 2000), meridian scanning photometers (Sandholt et al., 1992), poleward scanning coherent HF radar systems (Pinnock et al., 1993, 1995; Rodger et al., 1994; Rodger and Pinnock, 1997), and poleward pointing incoherent scatter radars (Lockwood et al., 1993b). Several studies using combined sets of such ground based data (Yeoman et al., 1997; Thorolfsson et al., 2000) have identified clear spatial and temporal relations between the various features of ionospheric and field-aligned currents, ionospheric plasma flow, topside electron heating, and precipitation. For situations during strongly northward directed IMF, similar transients have been observed to move equatorward (Sandholt, 1991; Øieroset et al., 1997), which strongly suggests that reconnection occurs on the dayside lobe field lines. For intermediate IMF directions (i.e. small $B_{Z}$ ), Sandholt et al. (1996, 1998a, b) and Lockwood and Moen (1999) have shown that a bifurcation of the cusp/cleft aurora can occur, were subsolar reconnection is observed to continue inspite of a northward IMF component. From the results of McCrea et al. (2000, see also references within), it appears that subsolar reconnection can continue to occur for as long as $B_{Y}$ is sufficiently large compared to $B_{Z}$, such that the IMF clock angle lies within $45^{\circ}$ of the magnetic equatorial plane.

The combination of the four Cluster spacecraft and global ground-based instrumentation will enable us to fully understand the dynamics and evolution of the cusp and to follow the various transient features which emanate from it as they make their way into other regions of the magnetosphereionosphere system. In this paper, we will present a wealth of coordinated ground-based and Cluster observations during an event which we interprete as a transient excursion of the cusp from an initial pre-noon location to the post-noon 15:00 MLT sector. Various sets of ground-based instrumentation will be used to identify the dynamics of a quickly evolving eastward directed flow-channel, which is associ-
14 Jan 2001: Cluster s/c 1 (Rumba) and DMSP F15

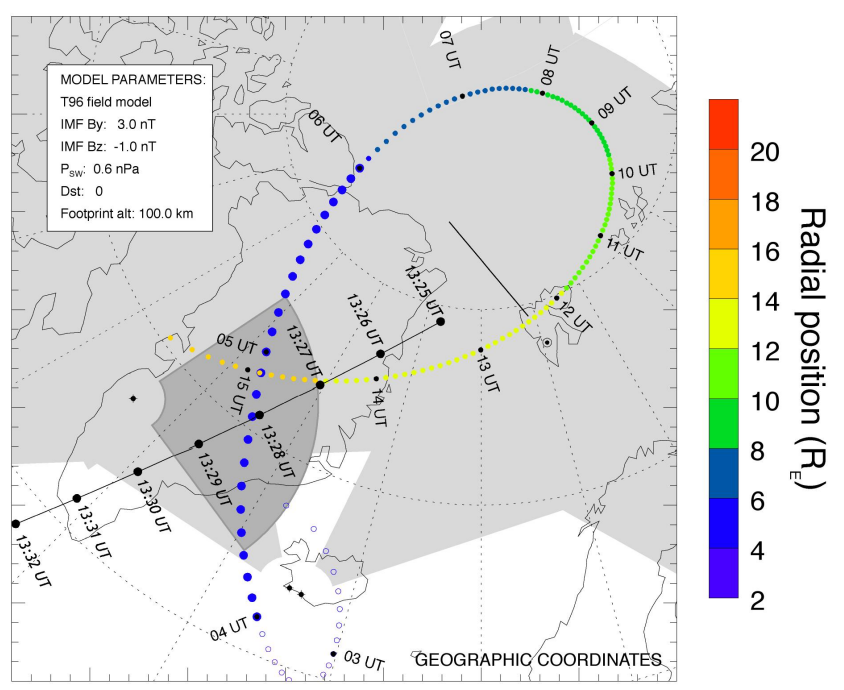

Fig. 2. Ionospheric projection of the Cluster and DMSP F15 orbit on 14 January 2001. Momentary locations are indicated every 30 min for Cluster and every minute after 13:25 UT for DMSP F15. The altitude of Cluster is given by a colour scale. Also marked are the field-of-views of some SuperDARN radar facilities, the range of the ESR northward pointing radar beam, and the scan coverage of the STF IS-radar. The coordinate grid is geographic.

ated with particle precipitation and ionospheric current flow. We will then inspect the Cluster data from multi-satellite sets of several instruments to investigate the usefulness of threedimensional measurements in space for the understanding of complex dynamical features.

Since we will use a very large variety of instruments, we prefer not to introduce them in a special section on instrumentation in order to avoid confusing cross references in the text. Whenever necessary, we will explain the main characteristic features of the utilised instrumentation in the text next to the presentation of the observations, and refer to more instrument-specific Cluster publications in this issue, or publications in the Satellite Ground-Based Coordination Sourcebook (ESA SP1198).

\section{Observations}

\subsection{Interplanetary conditions and overview of some Cluster and ESR observations}

On 14 January 2001, from about 07:00 UT onwards, the four Cluster spacecraft passed through the northern magnetospheric lobe and mantle on their way towards the dayside post-noon magnetopause. In Fig. 1, we show the detailed Cluster orbit in the Geocentric Solar Eccliptic (GSE) $X Y, X Z$ and $Y Z$ planes. The dashed and full blue lines indicate a model bow shock and magnetopause at $Z, Y$, $X=0$, respectively, and the red and green lines represent field lines connecting to either the southern or northern 


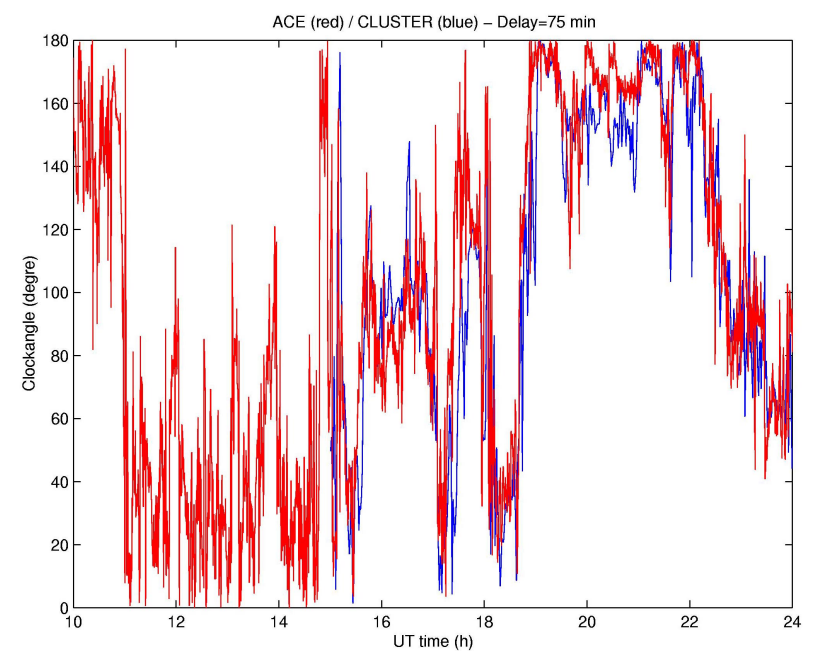

Fig. 3a. Overview of the IMF clock angle seen by Cluster FGM in the magnetosheath after 15:00 UT (blue) in comparison with the IMF clock angle seen by the ACE satellite at $220 R_{E}$ upstream from 10:00 to 24:00 UT on 14 January 2001 (red).

hemisphere ionosphere. We used a standard Tsyganenko-96 model (Tsyganenko, 1995), and chose the input parameters as IMF $B_{Y}=3.0 \mathrm{nT}$, IMF $B_{Z}=-1.0 \mathrm{nT}$, a solar wind pressure of $0.6 \mathrm{nPa}$ and $D s t=0$. According to the model, close conjunctions with the ESR and the Söndre Strömfjord (STF) radars were predicted for 12:00 UT and 15:00 UT, respectively, with a final exit into the magnetosheath at around 16:00 UT, corresponding to about 15:00 MLT. In order to allow for a closer inspection of the ground-based data with respect to the Cluster measurements in the following sections, we give in Fig. 2 the consecutive locations for the northern hemisphere magnetic footprints of the Cluster orbit from 04:00 UT to the expected magnetopause crossing at 16:00 UT. For later reference, we mark in Fig. 2 the location and extent of the ESR field-aligned and northward pointing antenna beams, the scan coverage of the STF radar, and the field-of-views of the SuperDARN radars in the relevant sector. In addition, we mark the orbit footprints of the DMSP F15 satellite during a passage over Greenland from 13:25 to 13:31 UT (see Fig. 24 below for the data from that passage).

If we want to interpret the detailed ground-based and Cluster data on the background of the prevailing solar wind conditions, we require as exact as possible knowledge of the direction and strength of the interplanetary magnetic field (IMF) and the solar wind pressure at the sub-solar magnetosphere. With no near-Earth solar wind monitoring satellite available for this study, we had to rely on measurements by the ACE satellite close to the L1 point, which is more than $220 R_{E}$ upstream in the solar wind. Using the fact that the solar wind clock angle (the IMF direction in the GSE $Y Z$-plane) is maintained during the passage of the IMF through the Earth's bow shock, we have carried out a cross-correlation between the interplanetary magnetic field angle at ACE and the angle of the magnetic field as seen by the Cluster FGM instrument
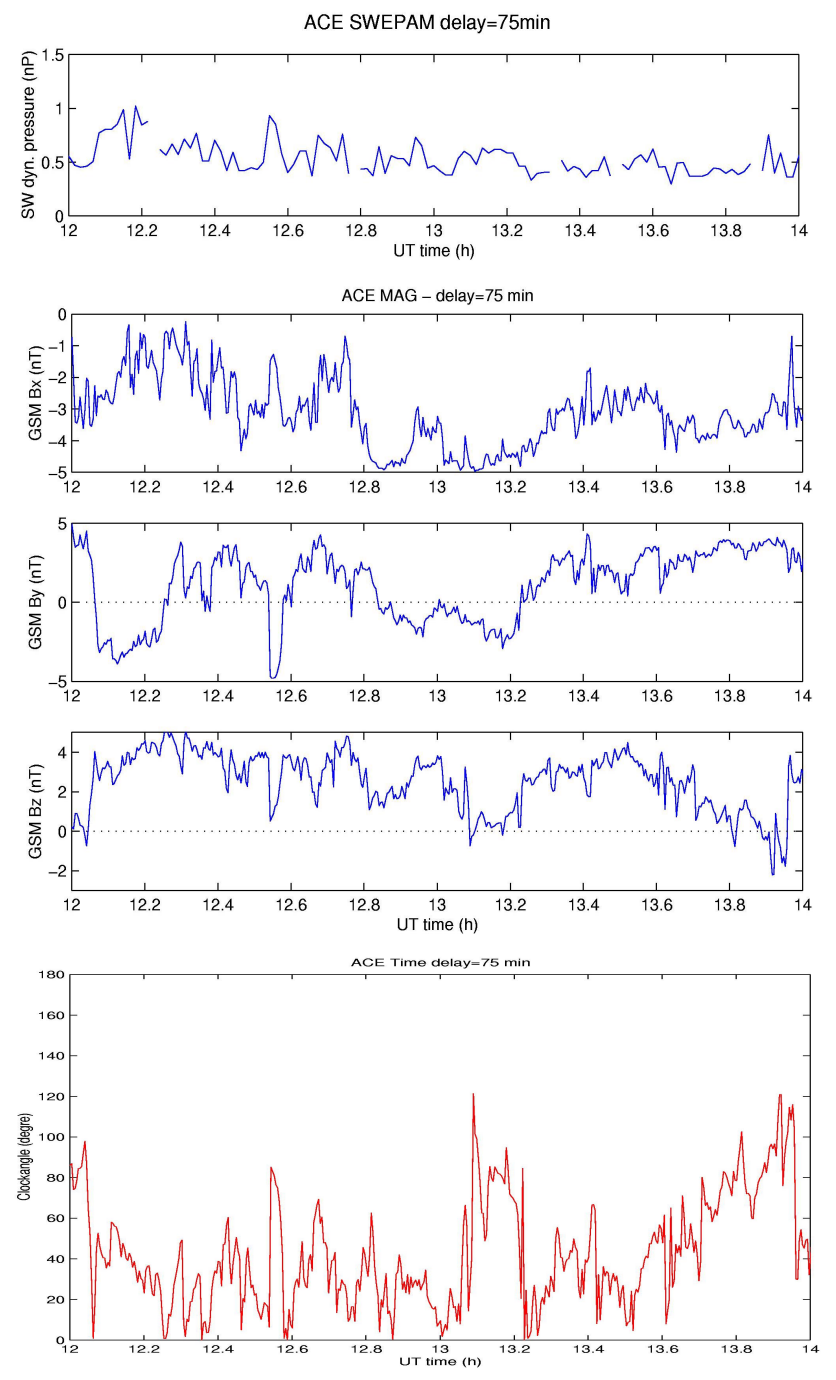

Fig. 3b. Detailed ACE data, shifted by a time-lag of $75 \mathrm{~min}$ as determined in Fig. 3a, from 12:00 to 14:00 UT on 14 January 2001. (From top to bottom: solar wind dynamic pressure, IMF $X, Y$ and $Z$ components in GSM coordinates, and IMF clock angle).

in the magnetosheath after about 15:00 UT (Balogh et al., 2001, this issue). In Fig. 3a, we show the excellent agreement of these two data sets by applying a delay of $75 \mathrm{~min}$ between ACE and Cluster when it is in the magnetosheath close to the magnetopause. The delay is very reasonable for a slow solar wind of $350-390 \mathrm{~km} / \mathrm{s}$, as observed on 14 January 2001.

In Fig. 3b, we show for further reference a more complete set of relevant ACE data for the time interval studied below, now shifted by the lag determined in Fig. 3a. We can conclude that neither the solar wind pressure (top panel) nor the IMF $B_{Z}$-component (panel 4) reveal that this period could be particularly interesting for solar wind effects on the magnetosphere ionosphere system. Apart from a short-lived deviation of $B_{Z}$ to small or even slightly negative values, which moves the IMF vector into the equatorial plane (so the clock angle is near $90^{\circ}$, bottom panel), there are no large indi- 
cations of solar wind forcing at all. The deviations in the clock angle are associated with negative excursions of the $B_{Y}$-component (panel 3), and the $B_{X}$-component (panel 2) is negative throughout the interval.

Using the inferred time shift of $75 \mathrm{~min}$ between the solar wind variations seen at ACE and their expected effects on the dayside magnetopause, we can easily understand the basic characteristics of EISCAT ESR and Cluster CIS observations during the entire northern hemisphere orbital portion on 14 January 2001. In Fig. 4, we show in a multipanel presentation the IMF $B_{Z}$ component seen at ACE with a delay of 75 mins (top panel), the electron density as seen by the ESR northward pointing and field-aligned antennas (panels 4 and 5 , respectively), and in the bottom panel, magnetospheric ions as measured by the CIS experiment on Cluster spacecraft 3 (Rème et al., 2001, this issue). The ESR facility and its data products are described in more detail below. From this figure, a number of observations can readily be made. During the period of primarily southward directed IMF from 07:00 to 11:00 UT, both the field-aligned and northward pointing ESR antennas are passed by frequent poleward moving events of increased ionisation. These events, and in particular those marked in Fig. 4 with a red bar, are studied in detail in a parallel paper by Lockwood et al. (2001a, this issue), who interprete them as signatures of bursty reconnection at a subsolar neutral line, which, during this period, must map to a location south of the ESR. In addition, during this time period, it can be concluded that the Cluster spacecraft passes from the relatively empty northern magnetospheric lobe into the plasma mantle, where multiple regions of enhanced ion fluxes pass the spacecraft (see again Lockwood et al., 2001a, this issue, for a more detailed discussion).

At 11:00 UT, the sudden northward turning of the IMF leads to a shrinking of the magnetospheric polar cap which in turn, results in a fast passage of the Cluster spacecraft through the poleward contracting field lines connected to the LLBL and finally reaching a trapped high-energy ion population, which is typical for the dayside Boundary Plasma Sheet (BPS). After 11:00 UT, the Cluster spacecraft remained most of the time in the BPS region, with the exception of a few shortlived encounters of the Low Latitude Boundary Layer (LLBL) plasma, containing lower energy magnetospeath ions (see arrows in Fig. 4). Again we have chosen to discuss these multiple encounters of field lines connected to the LLBL by Cluster, and coordinated ground-based observations of associated high-latitude features in a parallel paper (see Lockwood et al., 2001b, this issue).

After the distinct magnetospheric reorganisation occuring at 11:00 UT, even the ionospheric features seen by ESR change in character. The relative absence of electron density structures in the data from the field-aligned ESR beam implies that the open-closed field line boundary must have contracted to polewards of the ESR field line, or that the reconnection line has shifted in longitude such that newlyopened field lines no longer pass over the ESR field line. Furthermore, the still surprisingly frequent poleward moving events in the ionisation, as seen along the northward looking antenna beam, appear now much slower in their poleward velocity, which is indicative of a decrease in the overall convection velocity, as expected for weakly northward IMF.

The next dramatic event occurs at about 13:30 UT, when ESR records a series of poleward moving ionisation features of a rather different character than any of the previous ones. An initial rather broad poleward moving enhancement of the electron density is followed by a sharp channel of decreased ionisation, which is directly followed again by quite a narrow ionisation increase, apparently originating at far lower latitudes than any of the previous events (see a higher resolution presentation of this data in Fig. 13). During this transient event at the ESR location, the CIS instrument (located just off the Greenland's east coast) detects a short-lived but nevertheless complete drop out of the trapped high energy BPS plasma simultaneously with large fluxes of magnetosheath ions, a signature typical of the magnetosperic cusp (Smith and Lockwood, 1996). As we will show below, all other instruments on Cluster see features typical for the magnetospheric cusp at this moment. The nature of this sudden cusplike activity at 15:00 MLT, i.e. well away from any expected nominal cusp location, is the main topic for the following comparative study of Cluster and ground-based data.

The final noteworthy observation in Fig. 4 is the exit of the Cluster spacecraft into the magnetosheath at 15:00 UT, i.e. about one hour earlier than predicted by the model, using a standard solar wind parameter set. The ESR observations stop at about this time due to a scheduled end of operation.

\subsection{Ground-based observations during the transient cusp} event around 13:30 UT

In the following section, we will utilise a complete set of ground-based observations to study the global and mesoscale evolution of magnetospheric convection and ionospheric current flow, which consequently leads to the surprising event of cusp-like plasma seen by Cluster at 15:00 MLT. The most appropriate ground-based tool to provide a global view of the instantaneous convection pattern and its dynamical development is the Super-Dual Auroral Radar Network (SuperDARN, Greenwald et al., 1995), which now employs 4 overlapping radar pairs (i.e. 8 radar facilities) in the northern hemisphere, covering the better portion of the northern polar cap and auroral zone. In Fig. 5, we show the locations and overlapping fields-of-view of these radars. For further reference, we also indicate in this figure the locations of key magnetometer stations within the CANOPUS (red squares; Hughes et al., 1997), Greenland (light-green squares; http://web.dmi.dk/fsweb/projects/chain/greenland.html) and IMAGE (blue squares; Viljanen and Häkkinen, 1997) networks of magnetometers. During the present study, these arrays of instruments are located in the dawn, noon, and postnoon sector, respectively. The darker green squares indicate magnetometers in the Russian Arctic, which are not used for this particular study. Note, however, that the IMAGE magnetometer network is part of the Scandinavian multi-instrument network MIRACLE (Syrjäsuo et al., 1998) which also em- 


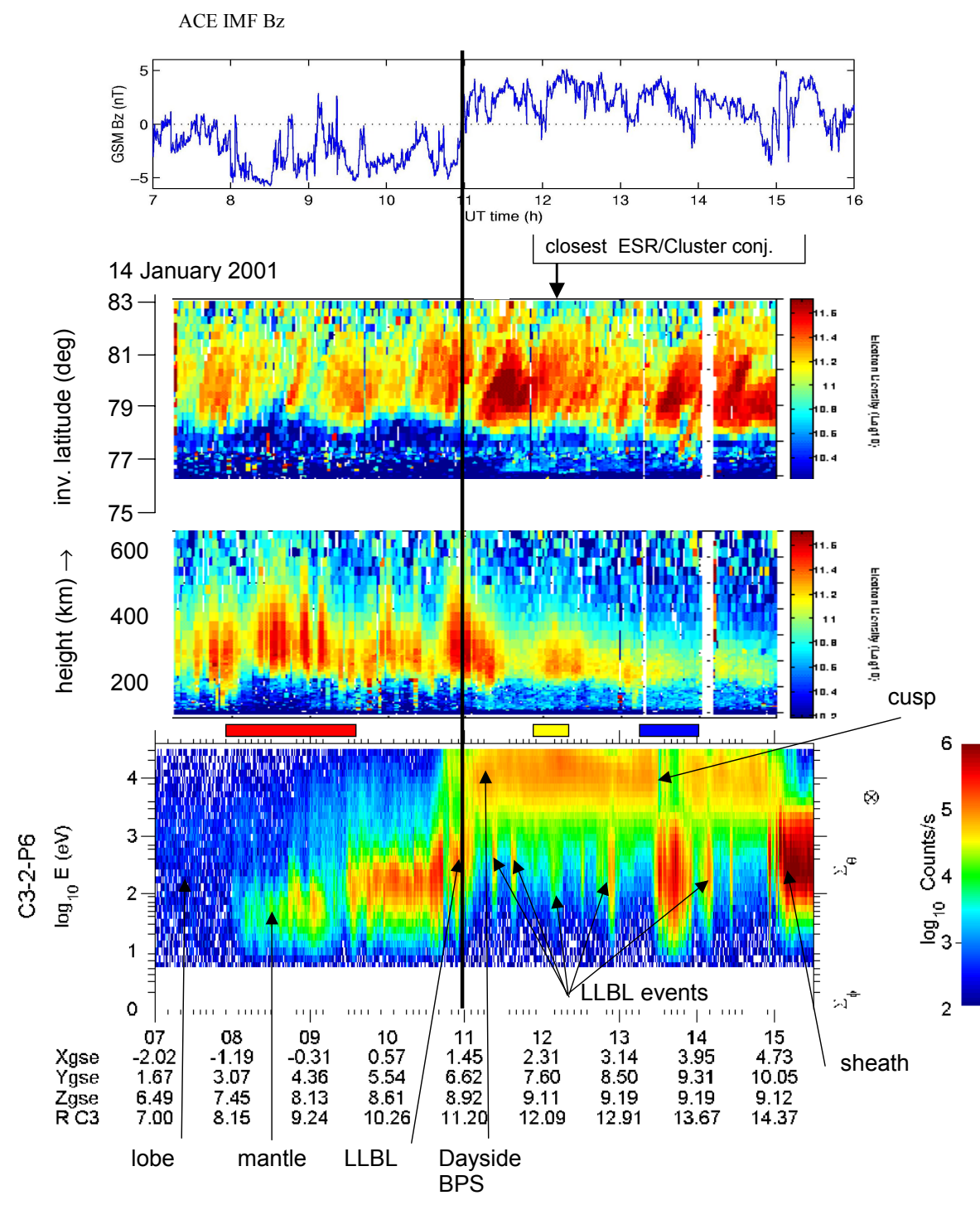

Fig. 4. Multipanel overview from 07:00 to 16:00 UT of ACE IMF $B_{Z}$ data (shifted by $75 \mathrm{~min}$ ), in direct comparison with EISCAT ESR measurements of the ionospheric electron density along a northpointing (i.e. versus latitude in panel 2) and field-aligned (i.e. versus altitude in panel 3) radar beam, and Cluster CIS data of the observed total ion flux on spacecraft 3 (bottom panel). Key events discussed in either this or two companion papers by Lockwood et al. (2001a, b, this issue) are marked with a blue, red, and yellow bar, respectively. Plasma features discussed in the text are labelled with arrows and the northward turning of the IMF at 11:00 UT is marked with a heavy vertical bar. ploys a bistatic VHF radar and a number of all-sky cameras, the northernmost one of which will be used in association with the ESR data below (see Fig. 13). A similar coverage of radars and other instruments is achieved at southern high-latitudes (data not used in this study; see Greenwald et al. (1995), and Opgenoorth and Lockwood (1997) for details).

By using the line-of-sight velocities of all 8 individual radar pairs, it is possible to derive a realistic estimate of the global convection flow by fitting the observed flow patterns to a convection model characteristic for the prevailing solar wind conditions (see Ruohoniemi and Baker, 1998, for more details of this method). In Fig. 6 (panels a to h), we show eight selected instantaneous convection flow patterns as derived from the data of the northern hemisphere SuperDARN radar network, using information about the solar wind from the ACE spacecraft delayed by $75 \mathrm{~min}$. The clock angle and intensity of the applied IMF is indicated in the small dial at the top right corner of each image. The original data stems from radar scans of $2 \mathrm{~min}$ in duration, which determines the time resolution of these global flow patterns. The velocities shown range from 0 to $1000 \mathrm{~m} / \mathrm{s}$, according to a colour scale in the top left corner of each image.

From these images, we see that at 13:22:24 UT the throat of the dayside two-cell convection pattern, the most likely position of the magnetospheric cusp, was located at a prenoon position over eastern Canada. Northern Greenland and the polar cap north of Svalbard are covered by a broad region of anti-sunward convection, representing the poleward part of the evening sector convection cell. The nightside portion of the morning sector convection cell is located over northern Canada and Alaska. Generally, the auroral oval is contracted, as could be expected for a northward IMF condition. Two min later, at 13:24:26, a new region of northeastward directed flow appears at the nominal cusp location. However, we would like to point out that a very small indication of this new flow is already visible in the first image.

In the following panels $(13: 26: 28,13: 30: 32$, and 


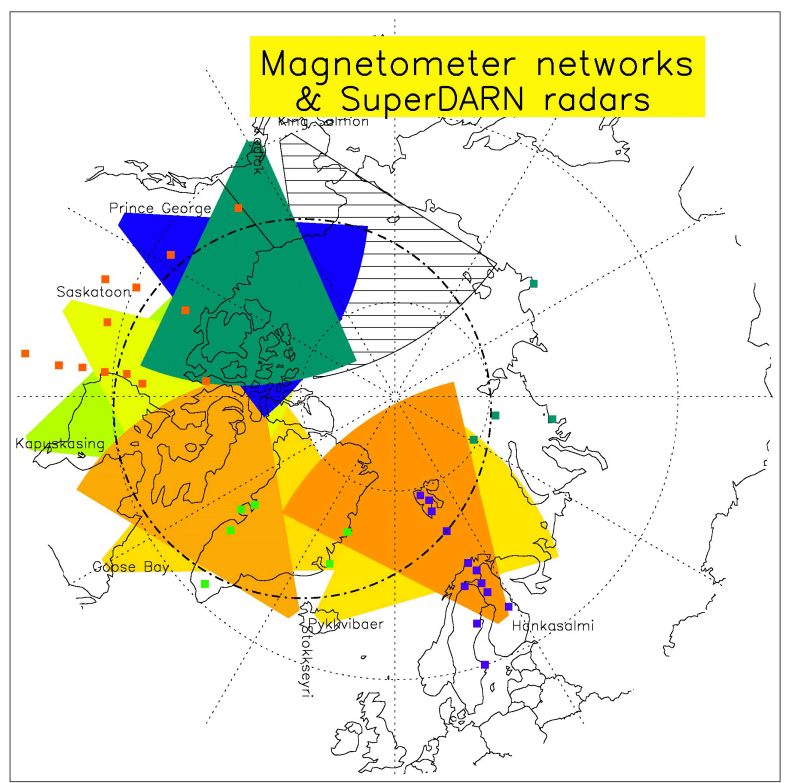

++ Southern Hemisphere : Holley, SANAE, Syowo South, Syowo Eost, TIGER, Kerguelen

Fig. 5. Northern hemisphere map illustrating the coverage of SuperDARN and magnetometer networks used in this study (see text for details). The shaded area is the field-of-view of a radar under construction.

13:32:34 UT), it can be seen how the new flow-channel grows, and finally connects the morning sector auroral oval flow over Canada across the north of Greenland to the postnoon polar cap flow north of the ESR. At 13:34:36 UT it is continuous from eastern Canada to the Arctic Ocean, north of Svalbard, and a strong westward flow-channel develops in the post-noon auroral zone, just to the north of mainland Scandinavia and the northern part of Greenland. Even the eastward directed auroral zone flows over mainland Canada and Alaska are considerably enhanced by this time. The new flow pattern has by now resulted in a peculiar narrow extension of the dusk sector convection cell, which appears very much like a superposition of a new shear-flow pattern on the standard quiet-time convection pattern.

To illustrate the nature of this new intense flow regime, we leave Fig. 6 for a while, and show in Fig. 7a the distribution of Joule heating in the northern hemisphere as calculated with the help of the Assimilative Mapping of Ionospheric Electrodynamics (AMIE, Richmond, 1992; Lu et al., 1997) and in Fig. 7b, the distribution of field-aligned currents at two selected times, namely 13:30 and 13:35 UT. For this study, the AMIE input consisted of data from all the SuperDARN and EISCAR ESR line-of-sight velocities, 4 DMSP satellites (both ion drifts and particles), 4 NOAA satellites (particle data only), and 94 ground-based magnetometers. AMIE parameter maps were derived with 5 min resolution. The first panel of Fig. 7a illustrates the character of the initial long flow-channel across the dayside portions of the two earlier convection cells at 13:30 UT. Only 5 min later, at 13:35 UT, does a second heat- (i.e. flow-) channel develop as an auro- ral oval return flow. As seen from the SuperDARN data in Fig. 6, its direction is westward and it lies at lower latitudes.

The same temporal sequence is apparent from the fieldaligned current distribution in Fig. 7b; at 13:30 UT, an initial new pair of field-aligned current sheets appears superimposed on the weak standard Region I and II currents. The current is directed downward at the poleward side and upward at the equatorward side, in order to imbed an eastward directed flow-channel and a westward directed ionospheric current flow (see also magnetometer data in Fig. 9). At 13:35 UT, this field-aligned current pair is more concentrated at higher latitudes, and a third, downward current sheet has developed equatorwards of the westward flow (eastward ionospheric current)in the post-noon auroral zone.

Returning to Fig. 6, the SuperDARN data shows that after the maximum phase of the transient event at 13:34:36 UT, the eastward directed portion of the new convection channel, i.e. the polar cap part, decays somewhat earlier than the westward directed auroral zone flow. After about 13:50 UT, the global convection has returned to a more normal undistorted 2-cell pattern now exhibiting again a clear convection throat over eastern Canada.

We are well aware of the fact that the data presented in Fig. 6 is quite strongly based on several model assumptions and represents only a best fit restricted by many individual line-of-sight velocity observations and a model convection pattern (Ruohoniemi and Baker, 1998). In order to illustrate that the observations described above are a true pattern seen even in the combined vector maps of individual radar pairs, we show in Fig. 8 data from the Goose Bay / Iceland West (Stockseyri) DARN radar pair. In these spatially limited, but more directly derived vector maps over Greenland, the earlier noted development and decay of a short-lived eastward (red vectors) convection flow-channel followed by the later development and decay of a westward (blue vectors) convection flow-channel becomes even more evident. Thus, we conclude that the data from direct bistatic vector measurements strongly support the content of the global convection maps derived by the method of Ruohoniemi and Baker (1998).

However, the EISCAT data in Fig. 4 clearly indicates a poleward progression of the new electron density feature at 13:30 UT, something that is not quite apparent from these time integrated vector maps and the AMIE model results. In order to further investigate whether SuperDARN data can support these ESR observations, we have inspected data along individual beams of the SuperDARN radars in search of poleward moving signatures (data not shown here). With varying clarity but nevertheless consistently observed in all 5 radars, a new regime of anti-sunward flow (away from the radars) was observed after 13:30 UT, which progressed poleward with time until about 14:00 UT.

There is, however, yet another and possibly even more reliable way of investigating flow enhancement events in the high-latitude dayside ionosphere. As already mentioned in the discussion above, intense flow-channel events are associated with field-aligned currents, electric fields, and last but not least, the precipitation of magnetospheric or magne- 


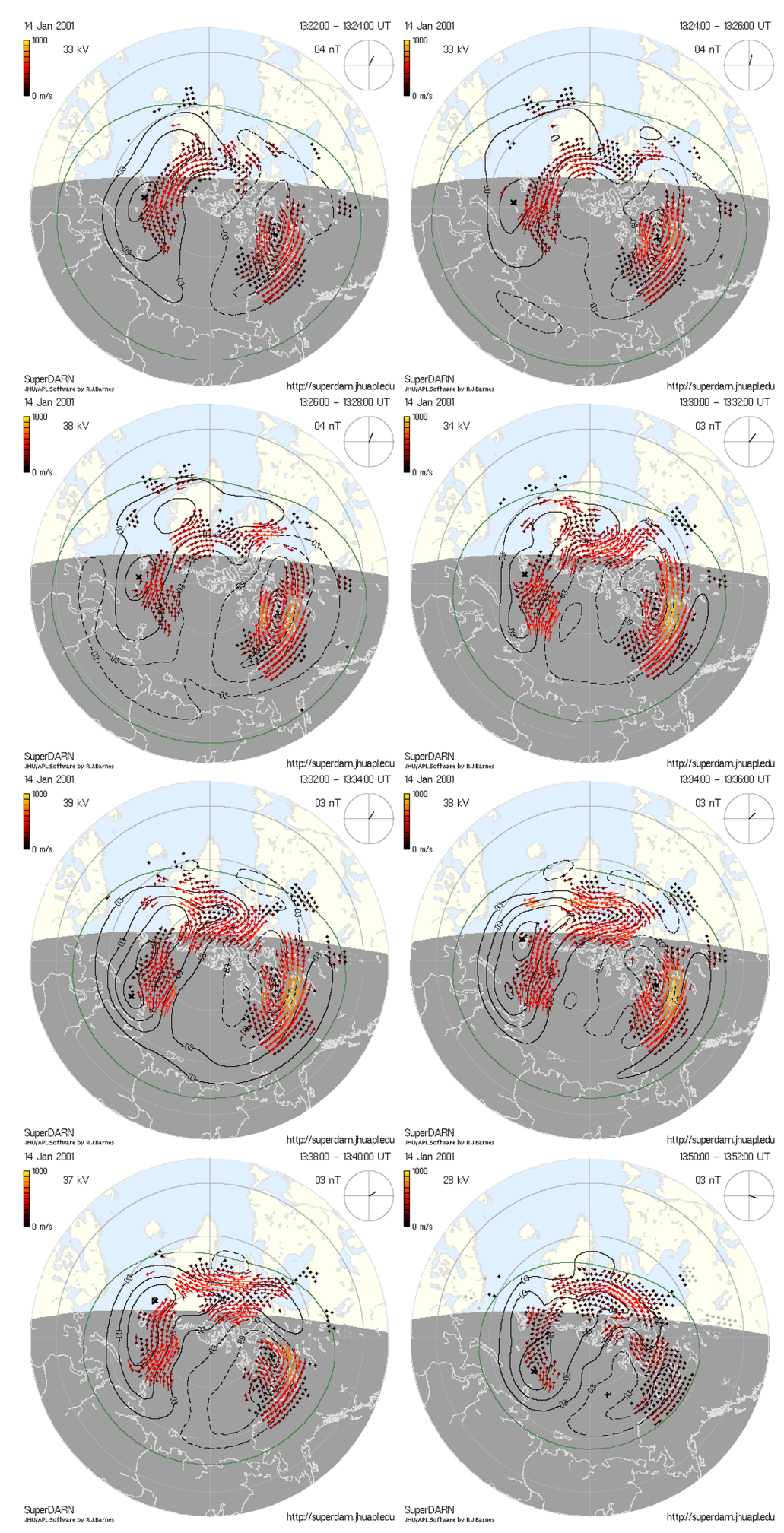

Fig. 6. Panel plot of 8 instances of global ionospheric convection as seen by the SuperDARN network between 13:22 and 13:52 UT on 14 January 2001. The flow vectors represents the fits of the actual line-of-sight velocity observations to a model convection pattern (black full and broken lines represents the electric potential contours), which in turn is constrained by the actual measurements and the solar wind influence on a convection model. The flow velocity is indicated by a colour scale and the derived cross-polar cup potential is given in the top left corner. The IMF data used is time-shifted ACE data (see dial in the top right corner of the images). 

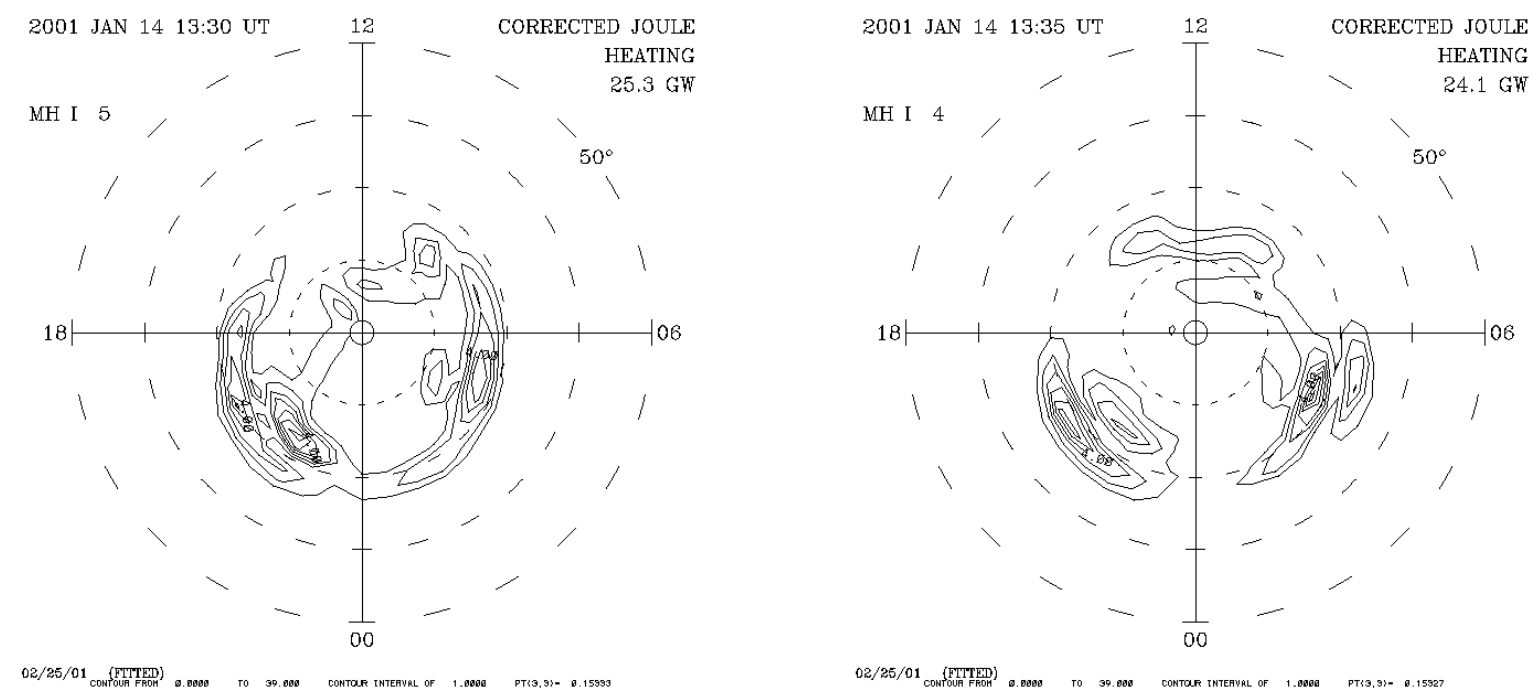

Fig. 7a. AMIE model results for two instances (13:30 and 13:35 UT) during the maximum phase of the flow-channel development on 14 January 2001. Global iso-contour patterns of the calculated Joule heating are shown in invariant latitude-MLT frames.

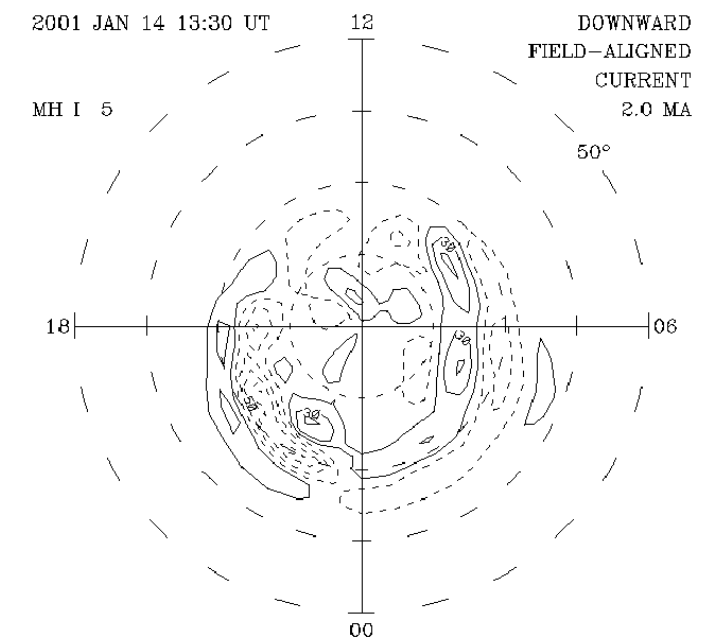

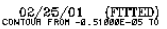

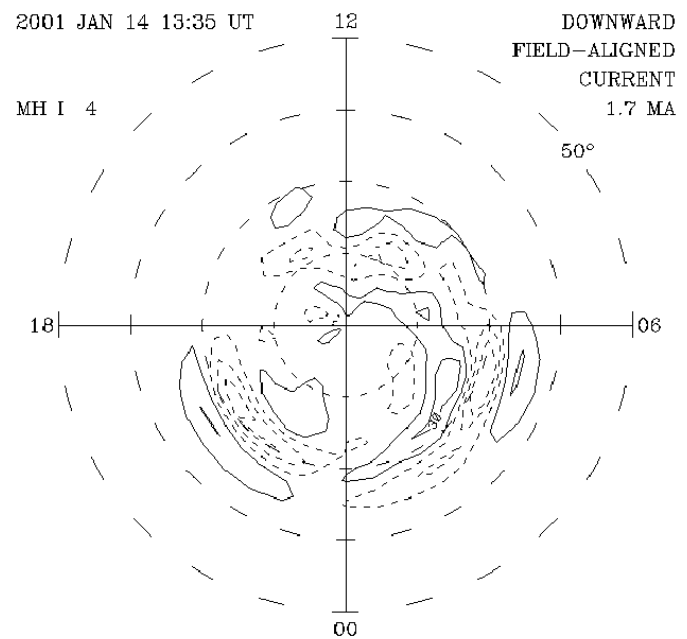

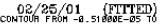

Fig. 7b. Global iso-contour patterns of field-aligned current flow (downward FAC - full contour lines; upward FAC - broken contour lines), derived using the AMIE technique for the same times and reference frames as Fig. $7 \mathrm{a}$.

tosheath particles into the dayside ionosphere. Therefore, it is obvious that these flow-channels must be associated with ionospheric currents, which in the case of predominant Hall current flow, will be detectable by magnetometer networks as current channels, but with opposite directions, as compared to the flow-channels observed by the radars (Stauning, 1995). Indeed, by inspecting magnetic records from highlatitude stations within the CANOPUS Churchill line, the Greenland westcoast line and the IMAGE central meridian from Svalbard to southern Finland, we find that all stations around 13:30 UT are under the influence of alternating eastward and westward current flows (original magnetogram data not shown here). In these magnetograms, we find a distinct phase-shift of the peak disturbances with higher and higher latitudes, indicating a poleward progression of the associated current patterns, which we would like to illustrate in more detail.

In Fig. 9, we display the magnetic $X$-disturbance measured at the three meridional lines of magnetometers in a colour-coded latitude versus time plot. Red areas indicate eastward current flow and blue (or green) areas indicate westward current flow. Following Stauning (1995), we assume that ionospheric Hall currents are the main contributors to dayside high-latitude magnetic disturbances. We find that the blue-green areas are westward currents within the initial eastward flow seen by the radars, while the red areas would correspond to the later development of primarily westward convection flow at lower latitudes. It is striking how well these independent magnetic observations support the radar observations discussed above, but now with the addition of 


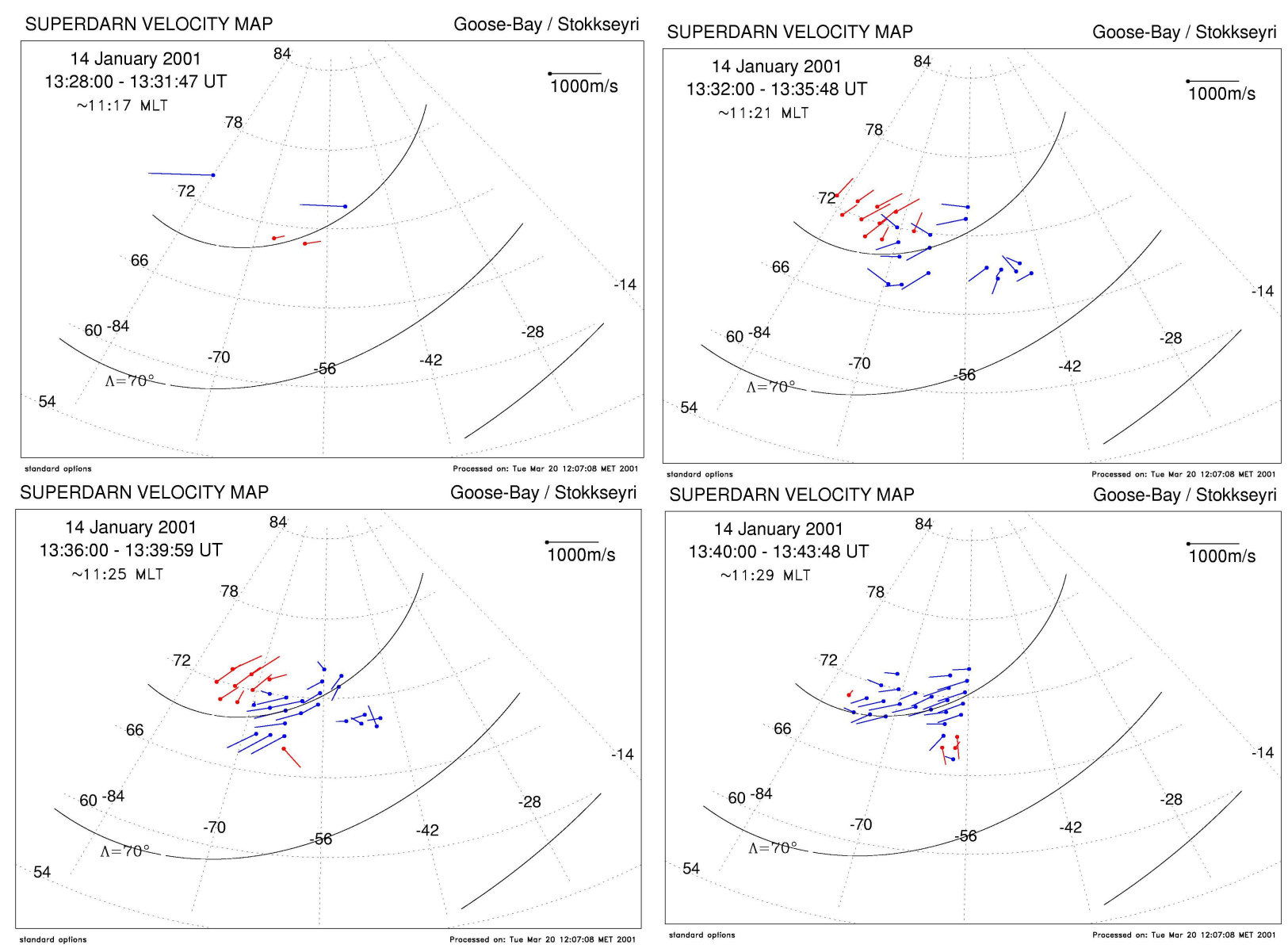

Fig. 8. Four examples of consecutive direct determinations of the horizontal ionospheric plasma flow from overlapping bi-static line-of-sight velocity measurements by the Stockseyri/Goosebay SuperDARN radar pair, overlooking the Greenland sector (compare with Fig. 2). The dot marks the origin of the velocity vectors, such that red vectors represent eastward plasma flow and blue vectors represent westward plasma flow.

a new perspective on the meridional motion of the observed feature, which was not as readily resolvable from the presentation of the radar data. The central panel of Fig. 9 corresponds to a meridian only slightly east of the nominal cusp location where we saw the first appearance of eastward flow in radar data shortly after 13:20 UT. In addition from this data, we see that a new region of westward current flow (eastward convection flow) appears just after 13:20 UT. It expands first equatorward, but after a few minutes, it expands poleward with a velocity of about $1.5 \mathrm{~km} / \mathrm{s}$. Not as clear, but in a similar manner, an initial equatorward erosion of preexisting eastward current flow and later a poleward progression of westward current flow is seen in the CANOPUS data (top panel). In the Scandinavian IMAGE data, the lack of stations between Svalbard and mainland Scandinavia (with the exception of Björnöya, BJN) gives insufficient data coverage at the relevant latitude. At 13:30 UT, all three meridian chains record the poleward motion of an eastward current channel (westward flow) which is located equatorward of the first current. The Greenland data show that this poleward expansion ceases at about 13:40 UT, reaching a northernmost invariant latitude of $80^{\circ}$. This observed ionospheric current pattern was of course one of the inputs to the AMIE results, yielding the derivation of a triple field-aligned current structure, downward at the poleward and equatorward edges, and upwardly directed in its central portion.

The SAMNET magnetometer network (Yeoman et al., 1990) consists of stations at both auroral and subauroral latitudes in the Iceland-UK-Scandinavian sector (see Fig. 10a for a map of SAMNET stations). In particular, data from the subauroral longitudinal line of stations is helpful in identifying the temporal and spatial development of highlatitude phenomena. The distant effects of three-dimensional substorm current wedges and other auroral zone features associated with localised field-aligned current flow create characteristic magnetic disturbances at subauroral latitudes. In Fig. 10b, we show the deflections in the magnetic $\mathrm{H}$ components during the key interval from 13:00-14:00 UT. At the westernmost stations (HLL, FAR, GML, YOR) almost independent of latitude, a positive deflection of the $\mathrm{H}$ component starts to develop just before 13:20 UT, when the first indications of a new flow-channel in the SuperDARN 

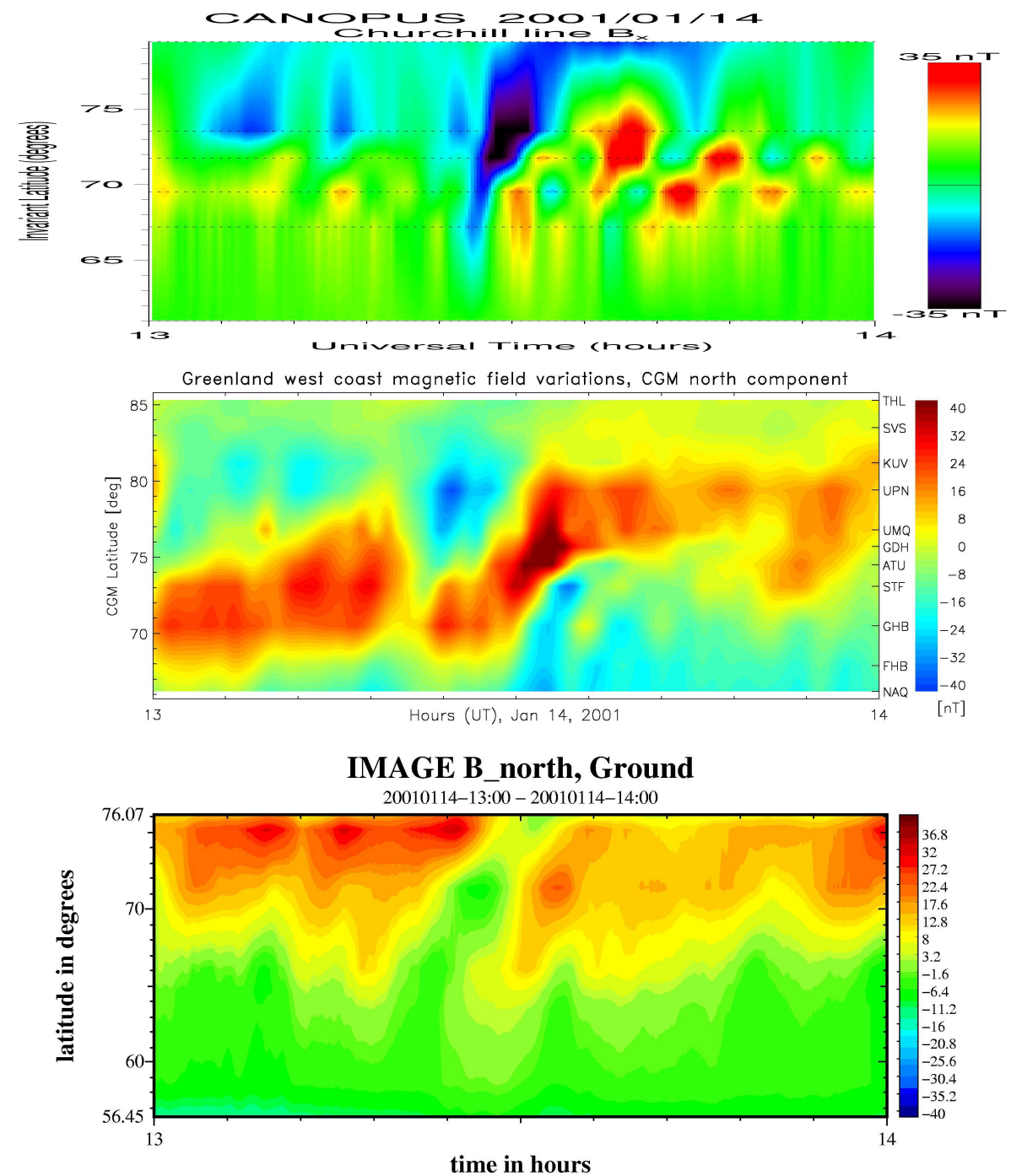

Fig. 9. Color-coded iso-contour plots of magnetic $X$-component disturbance on the ground as determined along magnetic meridians central to the CANOPUS (top panel), Greenland (central panel) and IMAGE (bottom panel) magnetometer networks. In these presentations blue areas correspond to westward and red areas to eastward ionospheric current flow. data over Canada are seen. This initial disturbance declines after 13:28 UT, reaches a minimum at about 13:32 UT, and is followed by a return to positive values by 13:40 UT. Along both sub-auroral longitudinal chains FAR-NOR-OUL and GMI-KVI-NUR-BOR, this initial bipolar feature in the magnetic $H$ disturbance is seen to propagate eastwards at a relatively high velocity $(1300 \mathrm{~km}$ in about $3 \mathrm{~min}$, corresponding to about $7 \mathrm{~km} / \mathrm{s}$ ). Similar high longitudinal motions of the convection throat during IMF $B_{Y}$ changes have been reported earlier by Greenwald et al. (1995). Along both longitudinal chains, the depth of the negative disturbance increases towards the east, indicating a later growth of this disturbance. The propagation of the feature clearly terminates at a longitude slightly east of NUR, since there is basically no time shift between NUR and BOR.

Even though this data confirms nicely the fast eastward propagation of a transient high-latitude event, its interpretation in terms of field-aligned current effects is very difficult. We have seen from the AMIE data that the new flow-channel is imbedded between two field-aligned current sheets, ex- panding towards the east, with the additional complication of the delayed formation (probably not expansion) of a more equatorward located downward directed current. It is clear that SAMNET must record the effects of this complicated development, but further conclusions will require a more detailed model analysis of the data, which is beyond the scope of this paper.

From Fig. 2, it becomes evident that at 13:30 UT both the US incoherent scatter radar at Söndre Strömfjord (STF, Kelly et al., 1995) and the EISCAT Svalbard Radar (ESR, McCrea and Lockwood, 1997) were in excellent locations to provide detailed observations of the different phases of the transient flow event. During this event, the STF radar was operated in a special mode, designed for coordinated observations with the ESR in conjunction with Cluster. This mode consists of an azimuthal scan at constant low elevation towards the northeast of the radar. In the top panel of Fig. 11, we display an overview presentation of the measured line-of-sight velocities during the entire period in question, together with more detailed line-of-sight velocities (left 


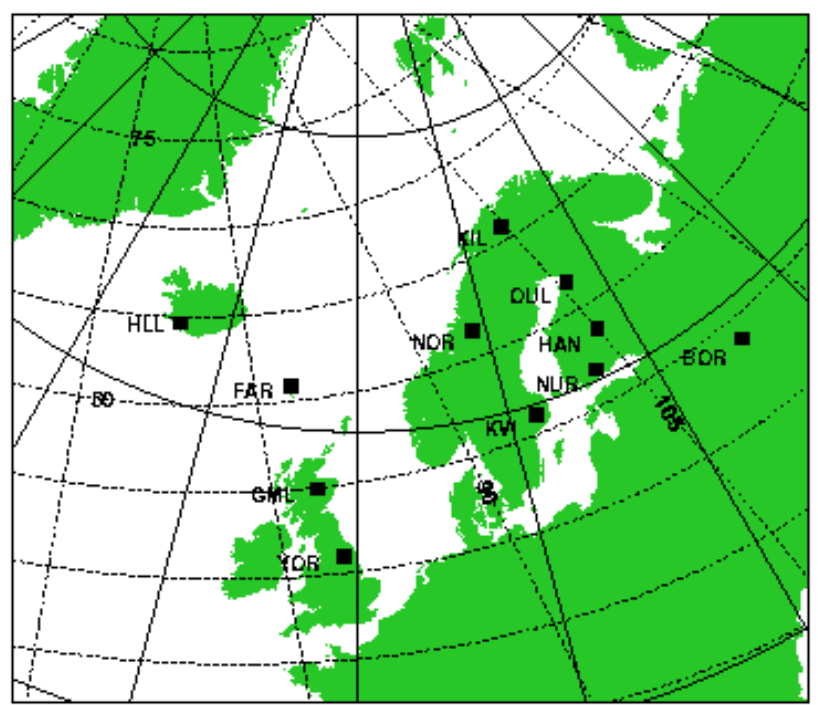

Fig. 10a. Map of stations in the SAMNET sub-auroral magnetometer array.

3 panels) and associated ion temperatures (right 3 panels) from three consecutive scans during the key interval from 13:28 to 13:39 UT. The scan duration is slightly more than $4 \mathrm{~min}$ and the scans are continuous, i.e. a scan towards lower latitudes (top two panels) is directly followed by a return scan towards higher latitudes (central two panels), and then equatorward again (bottom two panels). More information on this special mode of operation can be found at http://isr.sri.com/iono/cluster/cluster_experiments.html.

Already in the relatively coarse overview data in the top panel of Fig. 11, one can clearly identify the short-lived event of anti-sunward flow shortly after 13:30 UT (blue = away from the radar), which we have identified in all other data sets so far. Note that even though the axis is labelled as altitude, the main effects along that axis will be due to latitude variations, as the beam is pointed towards north and northeast at a low elevation. The detailed scans shown in the left lower panels of Fig. 11 illustrate that the flow event is restricted to the north-pointing directions of the scans, and that it is indeed very short-lived at this location. Some initial indications may be found in the first scan starting at 13:28 UT, and the flow-channel is fully developed when the second scan reaches this position again at 13:35 UT (i.e. close to the end time of this poleward turning azimuthal scan). The next return scan, passing that same region at 13:37 UT, already sees a clear decay. The same feature becomes visible in the right lower panels of Fig. 11, displaying the ion temperature along the radar beam. It is well-known from numerous incoherent scatter radar studies that short-lived flow enhancements have a pronounced effect on the temperature of the ionospheric ion population through the drastically increased ion neutral collisional heating. In the ion temperature data it is clear that not only the transient nature of the event stands out, but also comparing the lower two panels to the right, its poleward motion can be seen.

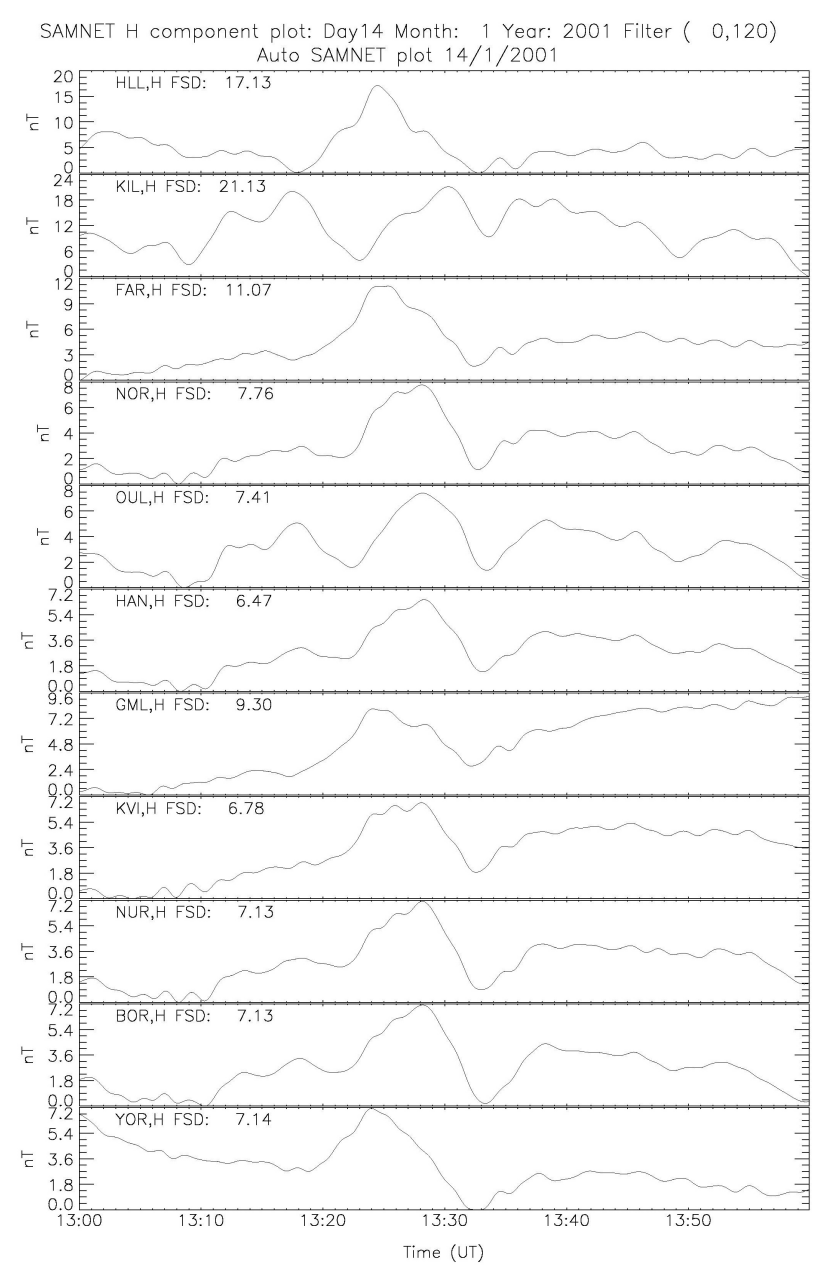

Fig. 10b. Horizontal component magnetograms from the SAMNET network, sorted from top to bottom along three longitudinal profiles at different latitudes (HLL-KIL, FAR-OUL, and GML-BOR).

This portion of the scan area of the STF radar was about $45^{\circ}$ in longitude to the west of the nominal Cluster footprint at that particular time, and about $30^{\circ}$ to the east of the location of the initial flow-channel, as seen by SuperDARN over Canada at 13:20 UT. At the same time, the northward pointing antenna beam of the ESR is only $15^{\circ}$ to the east and probably a few degrees to the north of the Cluster footprint (see Fig. 2, and discussion below). A spatial and temporal connection between the observations at these two key radar systems is provided by a Norwegian all-sky imager, located in Ny Ålesund. This camera is sensitive to red auroral emissions of $630.0 \mathrm{~nm}$. In Fig. 12, we show three selected images of red-line aurora, projected onto a map with the assumption of a central emission at an altitude of $250 \mathrm{~km}$. A more detail discussion of this optical data with respect to selected Cluster and low altitude satellite data is presented by Moen et al. (2001, this issue). The auroral data nicely illustrate how the features which were observed in the STF scan around 13:35 UT expand primarily eastward, but even slightly poleward, past the nominal location of the Cluster footprint at 

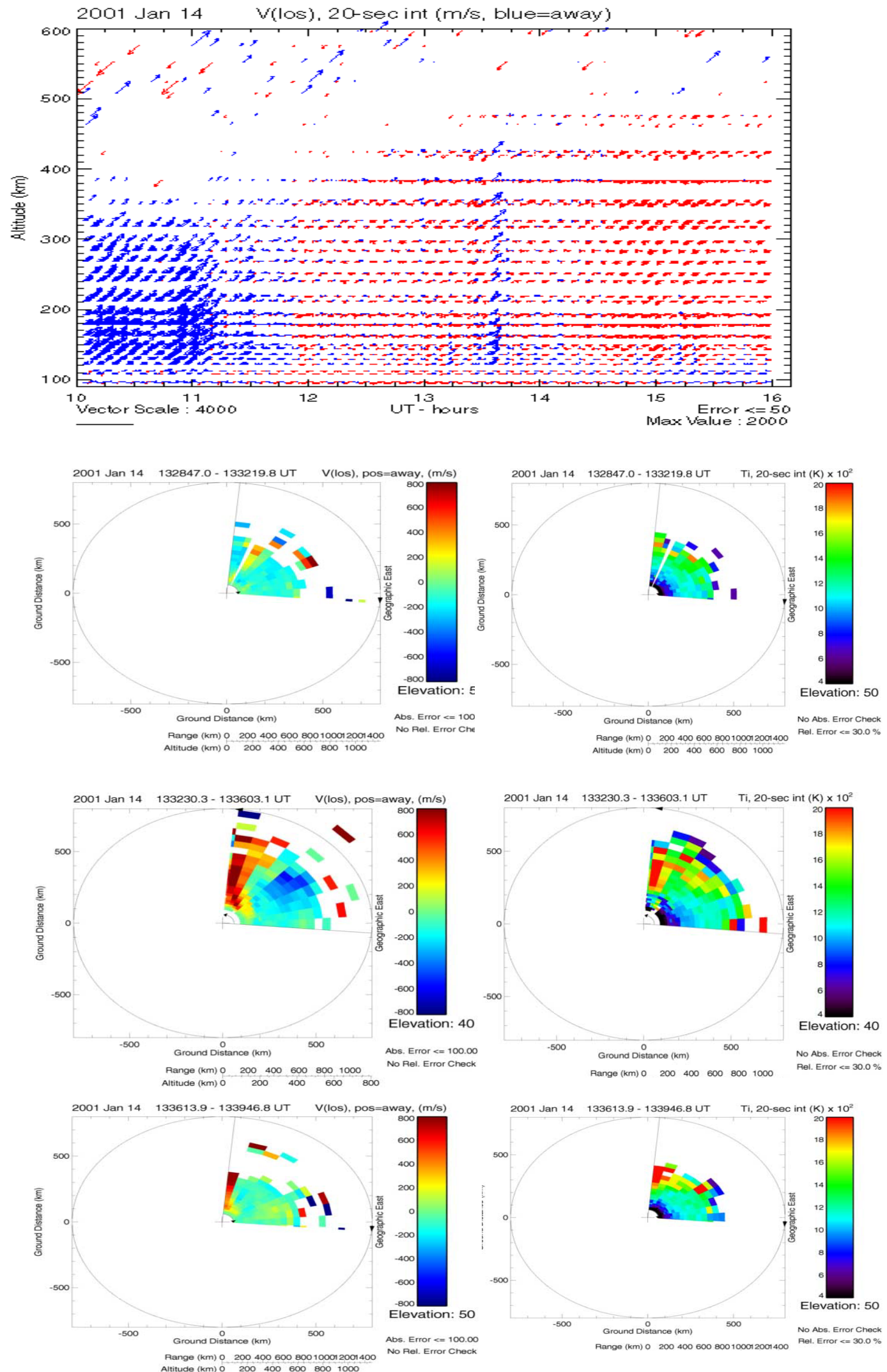

Fig. 11. Top panel: overview presentation of STF line-of-sight measurements along an azimuthal scan in the northeastern quadrant, plotted versus altitude and time (blue vectors represent flow away from the radar and red vectors represent flow towards). Bottom left panels: lineof sight plasma velocity measurements (red=away) for three consecutive scans from 13:28-13:47. Bottom right panels: ion temperature measurements (red=high $T_{i}$ ) for three consecutive scans from 13:28-13:47. North is to the top of the scan plots and east to the right. 

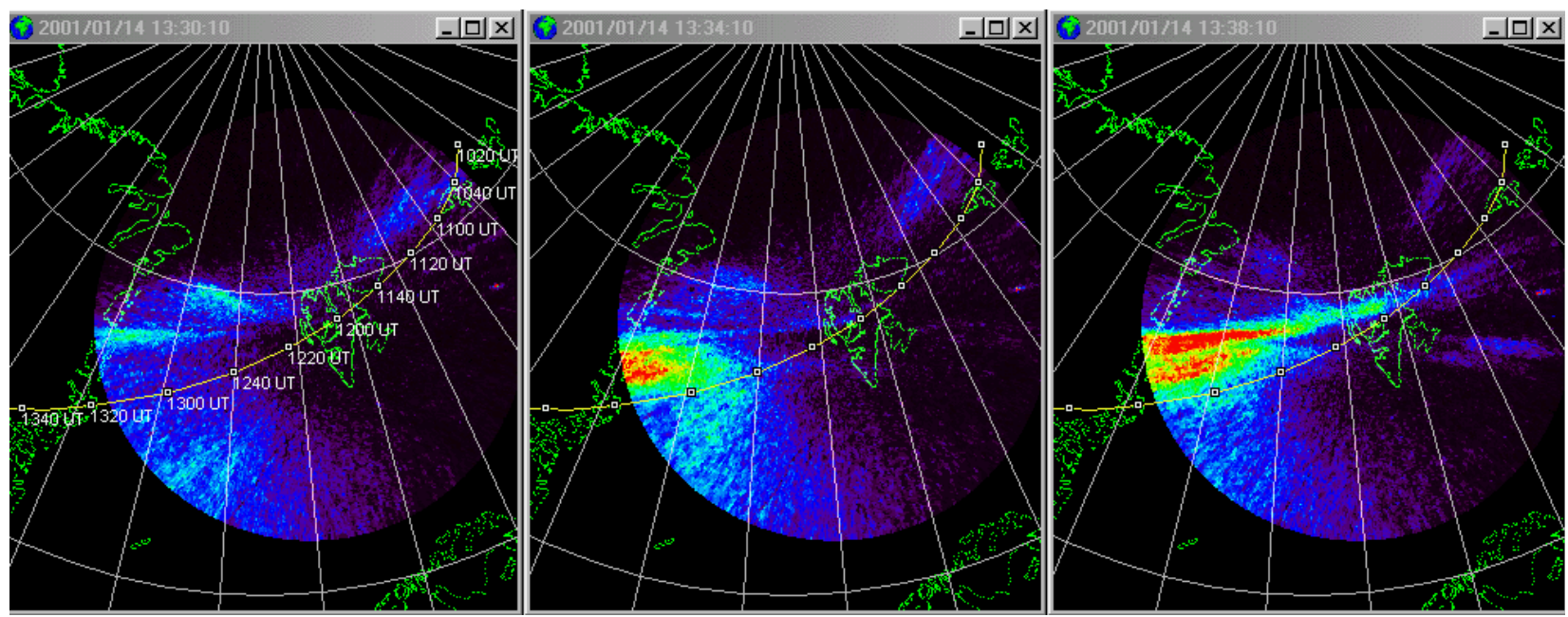

Fig. 12. Three selected all-sky camera images in $630.0 \mathrm{~nm}$ emissions from the Norwegian camera at NAL. The relevant portion of the projected Cluster orbit is indicated in the images (see time marks in the first image).

13:34 UT and into the vicinity of Svalbard at about 13:38 UT. By comparing the first and second images in Fig. 12, one realises that Cluster should have been affected by the auroral expansion at about 13:30-13:34 UT (see Moen et al., 2001, this issue, for more auroral images and also the following discussion in Sect. 2.3 for detailed Cluster data). The ESR should see the first effects somewhat delayed, i.e. after about 13:40 UT (see last image at 13:38 UT and the discussion below).

Detailed ESR data of electron density (the same data as in Fig. 4, top panel, but with a higher resolution) and ion temperature (the latter as a proxy of enhanced ionospheric flow) are presented in Fig. 13. In this data, the poleward moving character of the transient flow event is again obvious. The sharpest feature seen by the ESR is a poleward propagating depletion of the electron density (blue area at 13:40 UT in the top panel), coinciding with a region of enhanced ion temperatures, indicating enhanced plasma flow velocity (red/yellow area in the second panel). In the full set of ESR data (data not shown here), one can see that the ion flow direction in this channel of higher temperature is clearly away from the radar. We conclude that this sharp feature must be characteristic for the flow-channel itself. It is directly followed by an adjacent propagating region of enhanced ionisation (red narrow structure around 13:50 UT), originating at notably a lower latitude than any other electron density feature seen by the ESR during the entire Cluster passage (see also Fig. 4). We believe that it is created by new and more energetic precipitation, therefore affecting a lower altitude portion of the obliquely northward pointing ESR beam. In order to support this conclusion, we present in the bottom panel of Fig. 13 an optical keogram from the Italian all-sky camera (ITACA) at $\mathrm{Ny}$ Ålesund (i.e. $557.7 \mathrm{~nm}$ emissions along a meridional profile plotted versus latitude and time with the assumption of a central emission altitude at $110 \mathrm{~km}$ ). ITACA is part of the MIRACLE network. The heavy black line in the bot- tom panel of Fig. 13 corresponds to the lowest latitude in the data from the ESR oblique beam. By continuing the slope of the poleward propagating auroral forms in the keogram to that particular latitude (thin lines), one can readily associate the main flow-channel in the ESR data with a region void of auroral emissions (label 1). The channel of precipitation at 13:50 UT is associated with discrete $557.7 \mathrm{~nm}$ aurora (label 2). The fact that the aurora is green, i.e. resulting from particle precipition to altitudes of $110-130 \mathrm{~km}$, explains the ESR observations of increased electron densities at lower altitudes. Apart from this main event, the existence of a second pair of events is revealed in the combined presentation in Fig. 13. A weaker flow-channel (as recognised by the cavity in $n_{e}$, enhanced $T_{i}$ and a region void of aurora (label 3)) exhibiting only limited poleward expansion is followed by a region of enhanced precipitation and auroral emissions (label 4). This second sequence of events is actually apparent in detailed Cluster data as well and will be discussed below in more detail.

In finishing this comprehensive discussion of groundbased data sets, we note that the clear poleward moving events start at the lowest ranges of the radar at about 13:40 UT, i. e. somewhat after the onset of the poleward motion of currents and radar-echoes seen by other ground-based instruments (see Fig. 9) and the sudden onset of cusp-like precipitation in the Cluster data (Fig. 4 and discussion below). Furthermore, we note that the poleward velocity of about $0.5 \mathrm{~km} / \mathrm{s}$ derived for the flow-channel and the adjacent region of enhanced electron density events seen by the ESR is much slower than the poleward velocity of about $1.5 \mathrm{~km} / \mathrm{s}$ derived for the magnetic features seen at latitudes of the IMAGE chain between 13:30 and 13:40 UT.

In order to associate the features seen by the ESR radar with the magnetic features monitored by the IMAGE chain of magnetometers, we present the two data sets in a combined stacked plot in Fig. 14. When analysing Fig. 14, one 

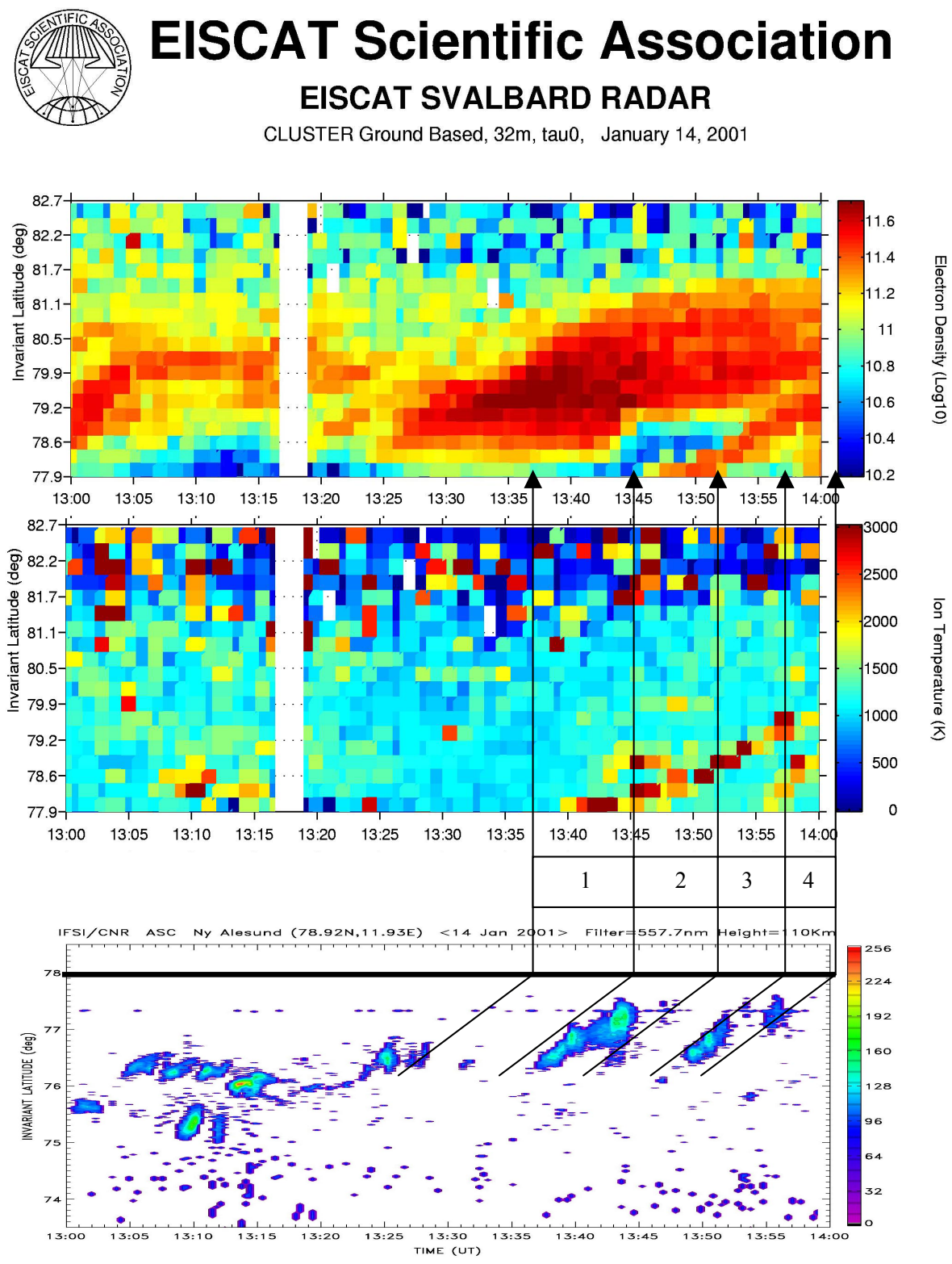

Fig. 13. Comparison of EISCAT ESR data versus latitude and time of electron density (top panel) and ion temperature (central panel) with a keogram from optical observations of $557.7 \mathrm{~nm}$ emissions by the Itaca all-sky camera, located just to the south of the range of the ESR poleward pointing beam. The heavy black line in the keogram marks the lowest latitude in the ESR data, and the thin arrows are guidelines to connect the regions void or filled with aurora to corresponding regions of low and high electron density (respectively, high and low ion temperature) in the ESR data. needs to keep in mind that the lowest latitude data in the poleward pointing ESR beam (77.9 $9^{\circ}$ Inv. Lat. in the top panel) is about $200 \mathrm{~km}$ to the north of the highest latitude data in the IMAGE chain $\left(76.7^{\circ}\right.$ Inv. Lat. in the bottom panel). The insert of Cluster CIS data in the central panel should be ignored for the time being, as it will be discussed in Sect. 2.3 below. Slanted and vertical lines in this stacked presentation are meant to assist the eye in connecting the key features of the various data. Obviously, the initial broad and fluctuating eastward current is associated with a similarly broad region of enhanced (and fluctuating) electron density in the ESR data. In correspondence to the earlier comparisons of coherent radar and magnetometer observations the flow-channel at ESR (decreased $n_{e}$ ) was associated at that time with a narrow region of westward current flow in the IMAGE data and a main precipitation region (enhanced $n_{e}$ ) with a new narrow eastward current, etc. for the second set of transients.

A comparison of Fig. 14 with Fig. 9 increases the confidence in this interpretation of physically associated features. Both in Canada and over Greenland, the initially fast poleward expansion of transient current channels around 13:30 UT decreased considerably after reaching about $80^{\circ}$ invariant latitude. In Fig. 14, this latitudinal boundary is located just poleward of the IMAGE chain, but right in the vicinity of the northward pointing ESR radar beam. Thus, the difference in the observed poleward velocity in the IMAGE and ESR data is explained by a global pattern that is not visible in the individual data sets. However, the observed features match very well.

In this section, we have presented data from a large network of ground-based stations to infer the dynamics of the ionospheric convection and several associated transient fea- 


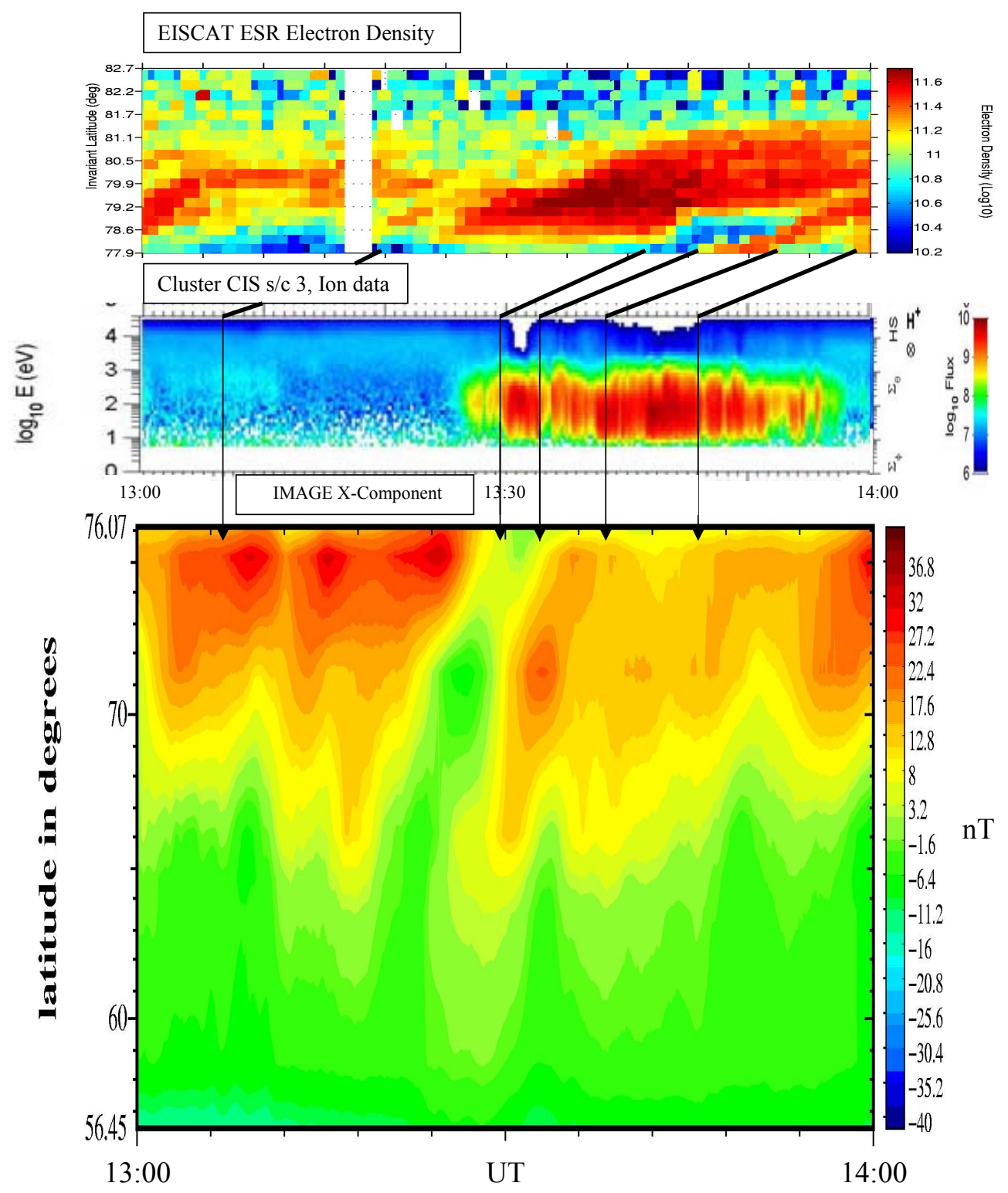

Fig. 14. Stacked plot of ESR electron density along the northward pointing radar beam (top panel, as in Fig. 13), total ion flux data from the CIS instrument on Cluster spacecraft 3, and the magnetic $X$-component disturbance along the central meridian of the IMAGE magnetometer array, ranging from southern Finland to just southward of the latitude of the ESR measurement range along the poleward pointing beam. The thin arrows mark the relation between features in the CIS ion data with regions of eastward (red) and westward (green) current flow in the magnetometer data. Heavier bars illustrate the possible continuation of the poleward propagation of these features towards the southernmost latitude of the ESR.

tures between 13:20 and 13:40 UT. In summary, we can state that a new eastward directed flow-channel, originating over Canada at about 13:20 UT, expanded during the following $20 \mathrm{~min}$ both eastwards and polewards, and finally reached the latitude and longitude of Svalbard at 13:35 UT. The change in the global pattern is best recognised in the data of the SuperDARN network, supported by the AMIE model. In more detail, the poleward motion of this eastward directed flowchannel was clearly detected in meridionally directed radar beams or individual magnetometer chains, and the eastward motion was confirmed not only by the use of data along sev- eral meridians, but also by an additional well positioned allsky camera and lower-latitude magnetometers. From the entity of these data sets we conclude that the predicted footprint of the Cluster satellites was engulfed by the leading northeastern edge of this new expanding flow-channel at about 13:30 UT. During the following interval of 20-30 min, Cluster remained to the west of Svalbard, at a comparable magnetic latitude with a fair possiblity to observe transient convection changes a few minutes before they affected the Svalbard region. 


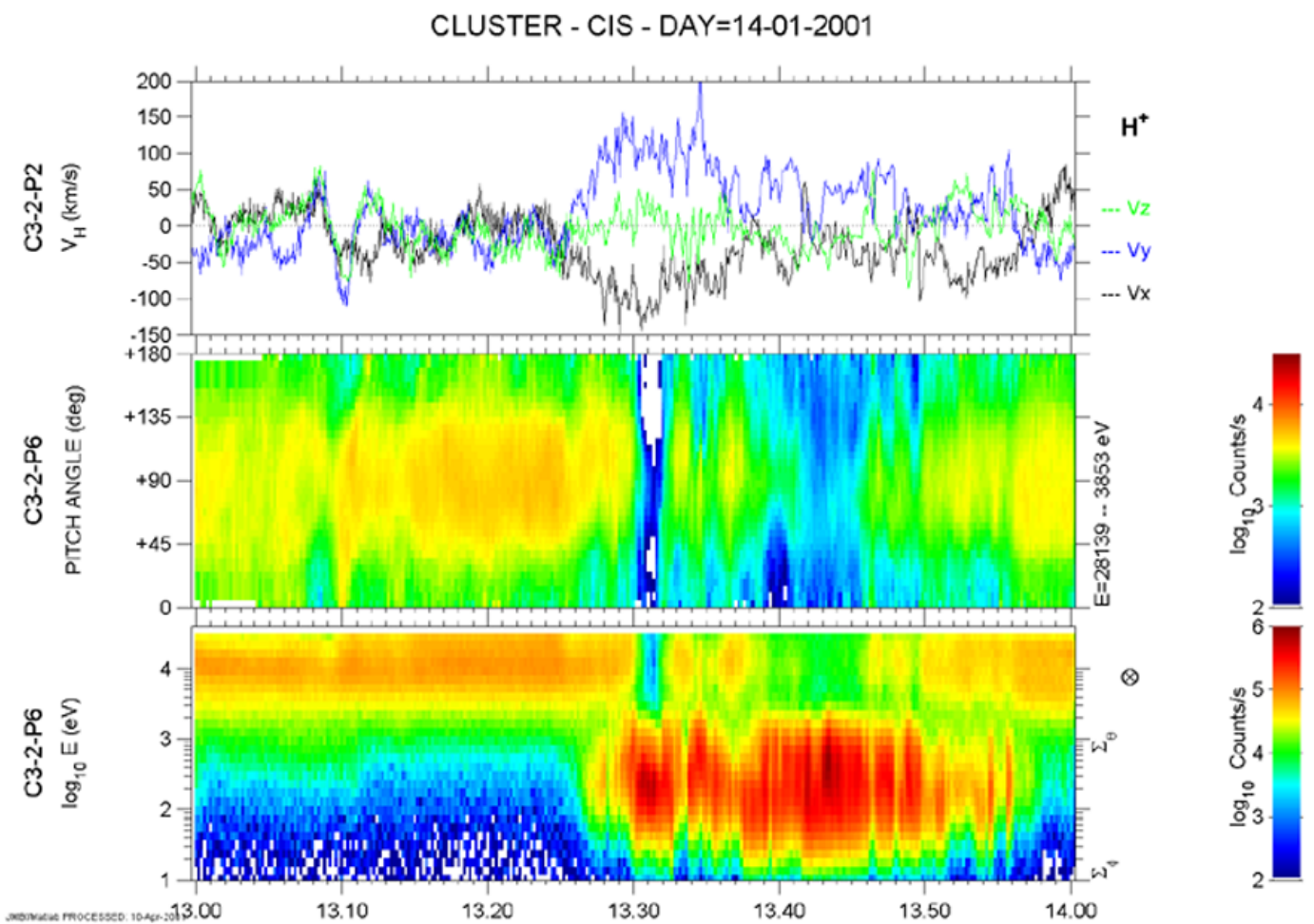

Fig. 15. CIS data on Cluster spacecraft 3 from 13:00 to 14:00 UT on 14 Janaury 2001, showing the bulk ion velocity in three components (top panel), the pitch angle distribution of ions in the 3.8-28 keV energy range (central panel), and the total ion flux versus energy and time (bottom panel).

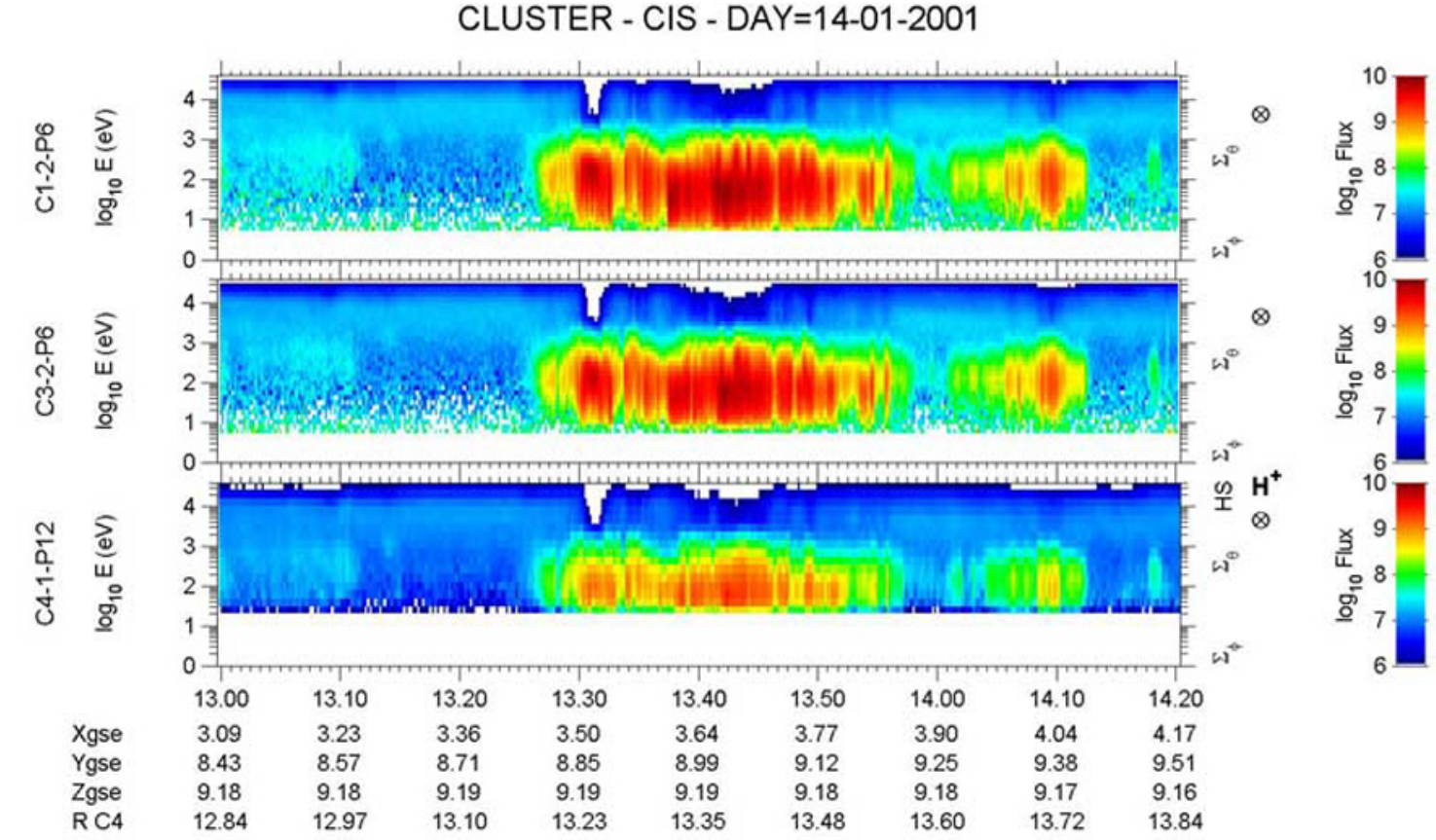

Fig. 16. CIS data of the total ion fluxes versus energy for Cluster spacecraft 1, 3, and 4, illustrating the variations between spacecraft 1,3 and spacecraft 4. 
2.3 Cluster observations during the transient cusp encounter around 13:30 UT

Figure 4 already gives an indication of the similarity of the transient features as seen by the ESR and the Cluster CIS instrument. Figure 14, shows the ESR (top panel) and CIS data (central panel), at much higher time resolutions than Fig. 4, concentrating on the hour of interest between 13:00 and 14:00 UT. In order to bridge the latitudinal gap between the ESR data and Cluster (just as the all-sky camera data in Fig. 13 bridged the gap between Greenland, Cluster, and Svalbard) we add in the bottom panel once more the data from the IMAGE magnetometer chain. With the aid of vertical lines, Fig. 14 illustrates that during the time interval from 13:30 to 13:50 UT, Cluster must have been passed almost simultaneously by the same structures of convection and precipitation, which passed over the magnetometers at the latitude of Svalbard. With a delay of the order of $10 \mathrm{~min}$, the same structures are seen to propagate into the northward looking ESR radar beam where they are observed to continue their propagation towards about $80^{\circ}$ invariant latitude (see detailed discussion above). The combined data also clearly shows that the main cusp-like features in the CIS data are associated with the first arrival of the eastward flow-channel. However, a careful inspection of the combined data reveals fine structure in the ion data, which might be associated with a second, but minor surge of cusp-like features at around 13:40 to 13:45 UT. As in the main event, its ionospheric features are a decrease in eastward current flow (westward electrojet or enhanced eastward plasma flow) and a depletion in electron density, which is indicative of a flow-channel (see also a clear second enhancement of $T_{i}$ in Fig. 13 at that time).

More detailed CIS data from spacecraft 3 in Fig. 15 shows the three-component $\mathrm{H}^{+}$velocities (top panel), the pitchangle distribution of trapped magnetospheric ions in the energy range of $3.8-30 \mathrm{keV}$ (central panel) and the standard total ion flux for reference (bottom panel). The central panel illustrates in more detail the complete drop out of magnetosheric particles at the time of arrival of the eastward flow-channel. The second partial drop out from 13:40:46 UT is also clearly contrasted from the time intervals of 13:33:40 UT and 13:46:56 UT, when the CIS instrument observes a mixture of magnetosheath and (somewhat depleted) magnetospheric ions. This must mean that the satellites are after the main event located in the magnetospheric boundary layer adjacent to the main body of the transient structure. The velocity data in the top panel show that CIS, probably as early as 13:26 UT, has entered the vicinity of the cusp region, detecting an enhanced, transient flow in anti-sunward direction. The curves indicate a flow primarily in the $-X$ (i.e. earthward) and $+Y$ (i.e. eastward) direction with a bulk flow velocity of up to $200 \mathrm{~km} / \mathrm{s}$. This flow event is observed until 13:37 UT, and is in agreement with the ground-based observation in the vicinity of the Cluster footprint. Successive fine-scale transients are superimposed on the average bulk flow. A diminution of flow can be observed around 13:32:33 UT, just adjacent to the main feature

\section{Spacecraft Configuration - 14 January 2001}

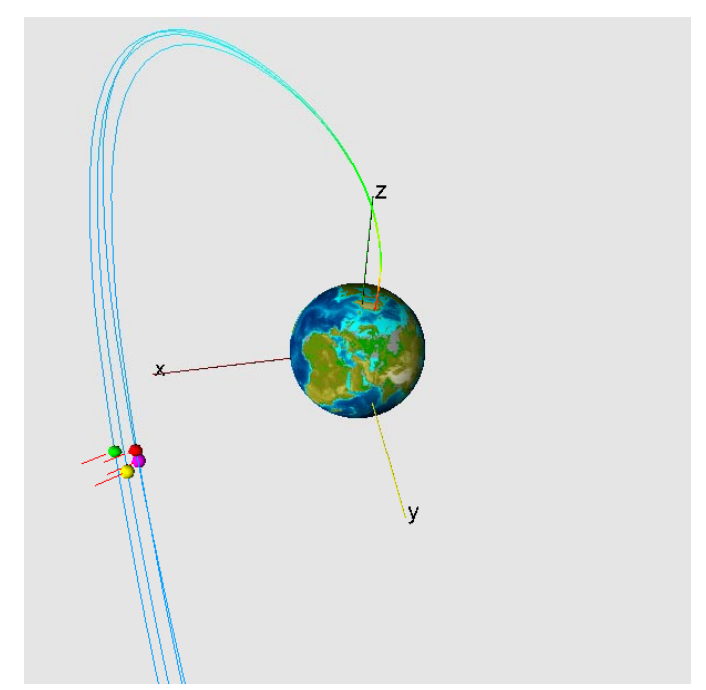

Electric Field (GSE X) - No Timeshift

Timeshift Applied
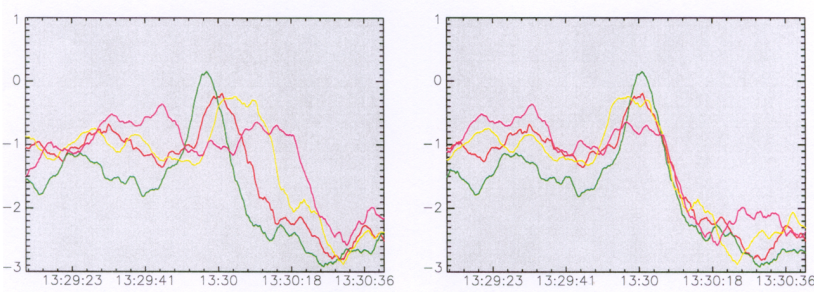

Fig. 17. Top panel: plot of the Cluster satellite constellation and the bundle of field lines that they are observing, as modelled by the Cluster orbit visualisation tool; left bottom panel: high resolution EFW data between 13:29:20 and 13:30:30 UT showing a transient in the total electric field measurements on all four Cluster spacecraft, and right bottom panel: the same EFW data but timeshifted according to a feature passing the satellites with a velocity of $v_{x}=-84, v_{y}=-6$ and $v_{z}=-38 \mathrm{~km} / \mathrm{sec}$. The OVT colourcoding of the satellites and the data is red, green, yellow, and magneta for spacecraft $1,2,3$ and 4 , respectively.

in the cusp-like ions. Even though we note that it is very difficult to map velocities from the magnetopause to the ionosphere along very distorted field lines, it is, nevertheless, interesting to note that this anti-sunward, duskward flow would correspond to an ionospheric convective flow of the order of $\leq 1 \mathrm{~km} / \mathrm{s}$, primarily eastward in direction, but with a clear poleward component.

So far we have presented Cluster data from only one satellite. The use of the full multi-satellite concept of Cluster should allow us to further understand the observed features as effects of a localised propagating magnetospheric structure. In Fig. 16, we show $\mathrm{H}^{+}$ion flux data from all three CIS instruments for the time interval from 13:00 to 14:20 UT (as described in more detail by Rème et al. (2001, this issue), the CIS experiment on spacecraft 2 suffers from a partial malfunction). In this resolution, the ion data of spacecraft 1 and 
3 appear almost identical, while clearly spacecraft 4 is engulfed in a much lower particle flux, arriving after a discernable delay. Nevertheless, all three satellites exhibit the discussed transient signatures of one complete (at 13:30:33 UT) and one partial (at 13:40:45 UT) drop out in the trapped ion population in conjunction with the arrival of magnetosheathlike plasma with energies of up to a few $100 \mathrm{eV}$.

In order to understand the differences in arrival time and the relative strength of the features in the CIS and other Cluster data, we need to know the location of the 4 satellites with respect to each other and in relation to the propagation directions inferred from the ground-based data. Fig. 17 shows the configuration of the Cluster spacecraft along a bundle of magnetic field lines originating from slightly east of Greenland, i. e. the satellite location at 13:30 UT. The top panel of Fig. 17 was produced using the Orbit Visualisation Tool (OVT, Stasievicz et al., 1992), and the colours "red", "green", "yellow", and "magenta" correspond to spacecraft 1, 2, 3 and 4, respectively. Referring to the discussion about the CIS multi-spacecraft data in Fig. 16 above, we can conclude that the central satellites of this configuration (spacecraft 1 and 3 ) are the ones which are fully affected by the transient precipitation. Spacecraft 4, which is located on a more poleward field line, appears to not be fully engulfed in this localised feature. To study this effect further, we present in the lower left panel of Fig. 17 a high resolution plot of the GSE $X$-component of the electric field from all 4 spacecraft for a pronounced transient feature at 13:30 UT. These electric field measurements are provided by the Cluster Electric Field and Wave experiment (EFW, Gustafsson et al., 2001; André et al., 2001, both this issue). Figures 17a and b use the same colour scheme as OVT for the electric field curves. It is easily concluded that the satellites are hit by this transient feature in the following sequence of spacecraft 2,1 , 3, and 4. Again, spacecraft 4 generally shows slightly different patterns than the other 3 spacecraft. A best fit timeshift analysis of the four curves results in the alignment displayed in the lower right panel of Fig. 17. From the applied shifts, one can calculate a resulting propagation velocity of the transient feature, $v(x, y, z)=(-84,-6,-38) \mathrm{km} / \mathrm{s}$. Considering the location of the satellites on the post-noon flank of the magnetosphere, a propagation primarily in the GSE- $X$-direction would be in agreement with the observed eastward, but also poleward motion of the feature on the ionospheric level. However, we would like to point out two caveats concerning detailed interpretations of this kind. First, we note that at this early stage of the Cluster data analysis, the exact amplitudes of electric field-components are not completely verified, and second, one should be careful in interpreting the relative arrival time of such extremely transient features at the satellite configuration. Similar sub-features have been seen to exhibit, with respect to the bulk motion, both backward and forward directed passages of the Cluster constellation. With this in mind, we should look out for more general gradients and their relative arrival time in other data at the various Cluster spacecraft.

A good candidate for the observation of more general trends is the local plasma density as derived from measurements of the plasma-frequency by the WHISPER experiments on Cluster (Decreau et al., 2001, this issue). Fig. 18 shows the plasma density at all 4 spacecraft during the $30 \mathrm{~min}$ of interest for this study, using the standard Cluster colourcode, spacecraft 1 (black), 2 (red), 3 (green), and 4 (magenta). Clearly the arrival of the cusp particles results in a short-lived enhancement of the plasma-density between 13:29 and 13:34 UT. Even the second event is recognisable as a less pronounced increase in the plasma density. From the blowup insert in the top left corner it can be seen that while several sub-events can have different relative arrival times at the spacecraft, the main trend in the plasma density, nevertheless, arrives in the same sequence as discussed above, namely red, black, green, magenta, corresponding to spacecraft 2,1 , 3,4 .

Data from the magnetic field instruments (FGM, Balogh et al., 2001, this issue) on all four satellites from 13:20 to 13:50 UT are presented in Fig. 19. The data are shown as three components in the GSE coordinate system. Several characteristic features can be recognised. At first, we note that the total magnetic field (see also Fig. 20) increases during the transient cusp encounter, while one normally would expect to observe a decrease in the outer cusp or magnetosheath region. The largest magnetic variations of about $25 \mathrm{nT}$ are associated with the arrival and "decay" of the transient cusp encounter at 13:30 UT. They are primarily in the negative $B_{X}$-component (somewhat less in the positive $B_{Z^{-}}$ component) which could indicate the effect of localised fieldaligned currents (see more detailed discussion in Section 3 below). Furthermore, a careful inspection of the most dramatic transient features in the $B_{X}$-component at 13:30 UT reveals the same "hit-sequence" of spacecraft $2,1,3$, and 4 by the magnetic transient, which is in good agreement with the observations of EFW, Whisper and CIS

Since we would like to understand the physical meaning of the observed variations in time and space, and the behaviour of the vector quantities with respect to the geometry of the feature itself, we have chosen a somewhat different presentation for data only from spacecraft 3 in Fig. 20. In the top panel, we plot for comparative inspection two selected energy channels of the Cluster electron instrument (PEACE, Owen et al., 2001, this issue). We use a red curve for the high energy trapped electrons and a black curve for the low energy magnetosheath electrons (see also Fig. 21 for a more complete presentation of PEACE data for this event). In the central panel, we plot the total electric field from EFW (red curve), and the total magnetic field from FGM (black curve). In the bottom two panels, we use our rough knowledge about the velocity and direction of the propagating feature to transform the temporal sequence of observations of vector components of $\boldsymbol{E}$ and $\boldsymbol{B}$ into spatial vectors along the path of the structure. We use GSE coordinates with an arbitrary origin at the satellite location, slightly before the encounter of the structure. This means that in these panels, time in the satellite frame runs from the top left to the bottom right. For further clarification of the lower right vector presentation, we 


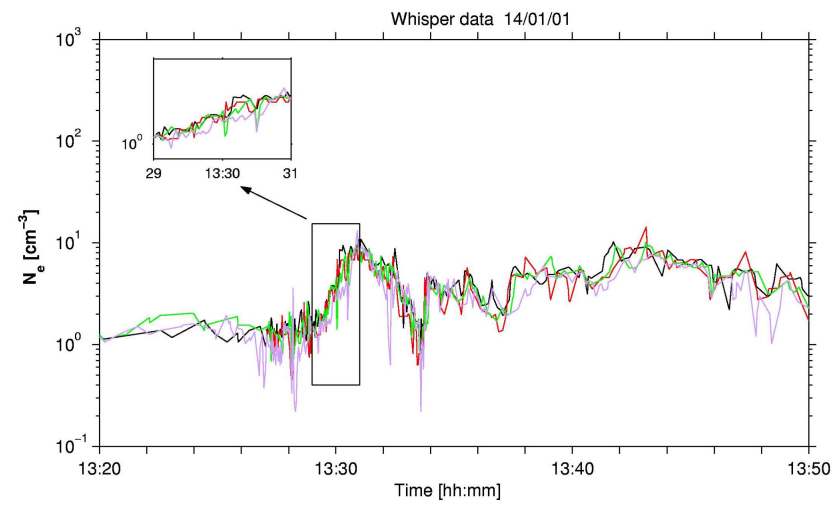

Fig. 18. Magnetospheric plasma density derived from measurement of the local plasma frequency by the WHISPER experiment on all four Cluster spacecraft for the key interval between 13:20 and 13:50 UT. Here we use the standard Cluster spacecraft colourcoding, which is black, red, green and magenta for spacecraft 1, 2, 3 , and 4, respectively. The inserted blowup around 13:30 UT allows for the identification of the temporal sequence of satellite encounters with an increase in the plasma density.

plot the variations in the component of $\boldsymbol{B}$ along the direction of the feature propagation as a shaded red area in the central panel. From this rather complicated but instructive figure, we can readily conclude a number of observations:

- As seen in the CIS ion data above, all parameters display an event with either a drop out, increase, or change in direction of field quantities at 13:30 UT. This is the time that we identified as the most probable encounter of Cluster with a propagating magnetospheric feature based on the combined ground-based data. This event is marked with a black line labelled "Magnetic Twist";

- The main effect on both the electric and magnetic field at 13:30 UT is not a shear, but rather an intensification and twist of the vectors in the direction of motion of the feature, i.e. towards the satellites;

- We note that the observed effect at this time is weakest in the electric field data;

- The feature is clearly a transient as it is observed for only $2-3$ min by all instruments;

- However, there are also clear and simultaneous observations of precursors. At 13:26 UT, marked with the first black line (labelled "Electric Shear") the electric field begins to intensify simultaneously with the CIS observations of increased plasma flow velocity. The bottom left panel illustrates that this intensification is clearly sheared with respect to the previous field direction before 13:25 UT;

- At about 13:25 UT, i.e. just before the increase and shear in the electric field, the high energy trapped particles are observed to drop out and reach a minimum at the time of the main event at 13:30 UT;
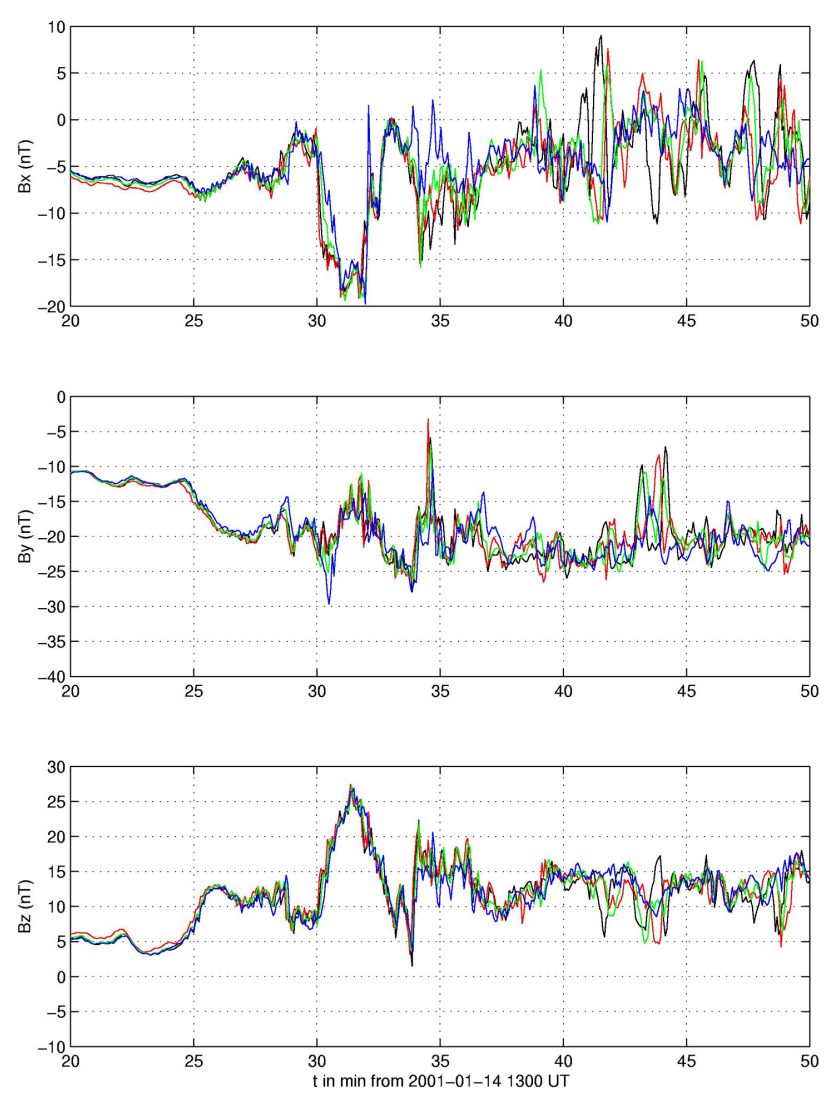

Fig. 19. Three component magnetic field data in GSE-coordinates from 13:20 to 13:50 UT from the Cluster FGM experiments on all 4 spacecraft. The color-coding is again standard Cluster, but here using blue instead of magenta for spacecraft 4 .

- Both the magnetic field and the magnetosheath-like electron flux (the same is actually true for the magnetosheath ion fluxes in the CIS data above) rise somewhat already at 13:25:26 UT, and remain on this partially enhanced level until after 13:40 UT;

- We note that the only observation which is not in agreement with traditional cusp observations is the rise in the magnetic field, which should display a decrease in the outer cusp (see discussion below).

In Fig. 21, we show more detailed data from the PEACE instrument. In the top panel, we display data from the high energy instrument (HEEA) on only one spacecraft, as there are no discernable differences in the HEEA data from the other 3 spacecraft. The other panels show data from the low energy instrument on all 4 spacecraft (LEEA; Panels 2-5). The two main events in the electric field (shear at 13:26 UT) and magnetic field (twist at 13:30 UT) are marked with vertical arrows. In this presentation, the drop out of the trapped electrons in association with the electric field variations is more pronounced than in the previous figure. It is also obvious that the first magnetosheath-like particles arrive shortly after this preceding event in the electric field, even though the bulk electron plasma arrives together with the ions at a 
well-defined onset at 13:30 UT, lasting for not more than 2-3 min. In addition, the most complete drop out of high energy trapped particles lasts only for this short period of time. The second smaller event at 13:40:44 UT, which we identified above in the ESR, IMAGE and CIS data, is also clearly recognisable in the PEACE data of all spacecraft. However, just as in the ion data, there is considerable fine structure between and around both of the main events, when varying fluxes of trapped electron populations are observed. Furthermore, this is confirmed (T. Fritz, personal communication) by data from the high energy electron instrument on Cluster, RAPID (Wilken et al., 2001, this issue, data not shown here). A careful inspection of the arrival times for the bulk magnetosheath electrons in even higher resolution data (not visible in Fig. 21) displays the same temporal sequence that was found for all other instruments. Again, spacecraft 4 encounters lower fluxes and fewer structures than the other 3 spacecraft.

As a last example of coordinated Cluster measurements, we present in Fig. 22 data from the high-frequency wave experiment (STAFF, Rezeau et al., 2001 this issue) during the interval of 13:20 to 14:05 UT. The top panel contains electric field wave spectra from $8 \mathrm{~Hz}$ to $4 \mathrm{kHz}$, and the central and bottom panels contain magnetic field wave spectra in the ranges of $8 \mathrm{~Hz}$ to $4 \mathrm{kHz}$ and $0-10 \mathrm{~Hz}$, respectively. Just as in the DC electric and magnetic field data in Fig. 20, the start of the event exhibits two key times. At 13:26 UT, the electric field wave activity increases gradually until the main event at 13:30 UT, when it increases in a second marked step. Both displayed frequency ranges of the magnetic wave data record a sharp increase of broad band waves at 13:30 UT, simultaneously with the main DC $\boldsymbol{B}$ increase.

In contrast to all the previous particle and field data, STAFF data resolves a clear structure in the main event, with only a transient decrease in both magnetic and electric field wave activity at 13:33 UT, the end time of the transient particle event. In general, the wave data displays a longer lasting activity during the initial event and the second smaller particle event is not clearly recognizable. The overall duration of a variable activity pattern between 13:25 and 13:57 is, however, identical with the particle data.

\section{Discussion}

The rich set of ground-based observations presented above is best explained by a sudden onset of enhanced pre-noon, but subsolar reconnection, which must have taken place sometime around 13:20 UT, as the first signatures of enhanced eastward flow are seen at that time by the global SuperDARN network (Fig. 6). First observations of equatorward expanding westward current, typically associated with eastward flow (Stauning, 1995) are made by the Greenland magnetometer array at the same time (Fig. 9). From Figs. 3b and 4 , it becomes obvious, however, that this reconnection pulse occurred during a period of extended northward IMF $B_{Z}$, generally positive $B_{Y}$, and negative $B_{X}$. The only pos- sible trigger event in the solar wind for the dramatic events described above is a minor excursion of $B_{Z}$ towards small values which, together with a negative excursion of $B_{Y}$, leads to a rotation of the IMF clock angle into the equatorial plane between 13:05 and 13:12 UT. According to Lockwood et al. (2000) and McCrea et al. (2000, see also references therein), such a configuration can allow for the occurrence of subsolar ( $B_{Z}$ southern type) reconnection in the northern hemisphere pre-noon region.

In order to illustrate the magnetic field geometry which may give rise to such a reconnection geometry, we show in Fig. 23 (left panel) the Earth's magnetosphere as seen from above the eccliptic plane. The dashed line represents the bow shock and the solid line is the non-reconnecting magnetopause. Magnetic field lines are drawn as arrows, here representing a $-B_{X} /-B_{Y}$ IMF topology. Thick arrows close to the highly bent newly-reconnected field lines (labelled A and B) indicate the direction of the curvature force towards the east. Fig. 23 illustrates that this topology favours reconnection in the noon and pre-noon sector resulting in an eastward directed plasma flow (Gosling et al, 1990a; Cowley 1981), which eventually must be projected down to the ionosphere. Based on this reconnection scenario, Lockwood et al. (2000) discuss how a number of consecutive reconnection pulses that originate in temporal sequence between the points A and B would develop in time, as seen at the ionospheric footprint of the reconnected field lines (Fig. 23, right panel). The uppermost line in all 4 displayed time-steps, i.e. the most equatorward boundary in Fig. 23 is considered to be the open/closed field line boundary, while the regions labelled 1-4 represent recently opened flux packages. From these snapshot sketches of the development of open flux, it can be seen that the reconnection pulse itself would initially lead to an equatorward erosion of closed flux tubes. Within this newly reconnected region the tension force of the field lines will give rise to the development of eastward directed flow-channels within the next $10 \mathrm{~min}$. As the tension force on the westernmost field lines is stronger, a pile up of the reconnected regions will occur during their propagation towards the east and later towards the pole. We note that such a behaviour is clearly reflected in the magnetometer data from the meridional chain closest to the east of the inferred origin of the initial reconnection site (central panel of Fig. 9). First there is an equatorward expansion of the new region of westward current, which suppresses the pre-existing eastward current regime, followed by a rapid poleward motion of both the westward and eastward current regime.

The unbending of newly-opened field lines is closely associated with the flow of field-aligned currents between the outer cusp and the ionosphere (Saunders 1989; Mei et al., 1995). The known pattern of such field-aligned currents, which imbed an eastward flow-channel for negative IMF $B_{Y}$ (Cowley, 1991b), is in good agreement with the initial development of a field-aligned current pair by the AMIE method (Fig. 7b). These "cusp"-FAC are downward on the poleward side and upward on the equatorward side. Thus, our observation of a later developing additional downward cur- 


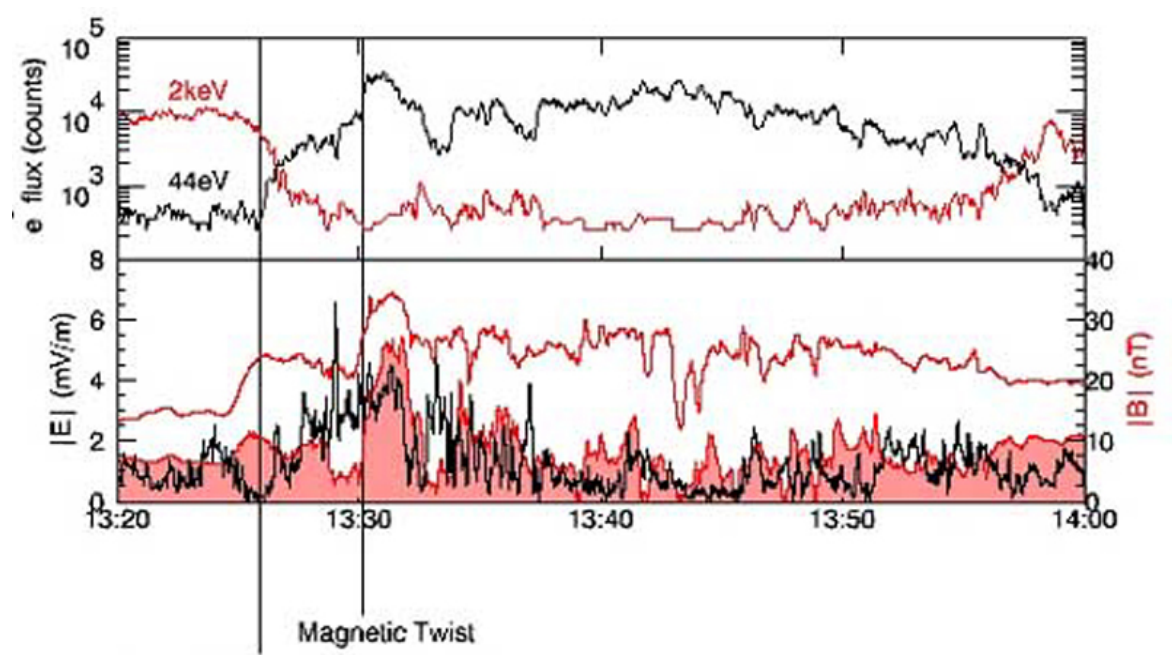

Electric Shear

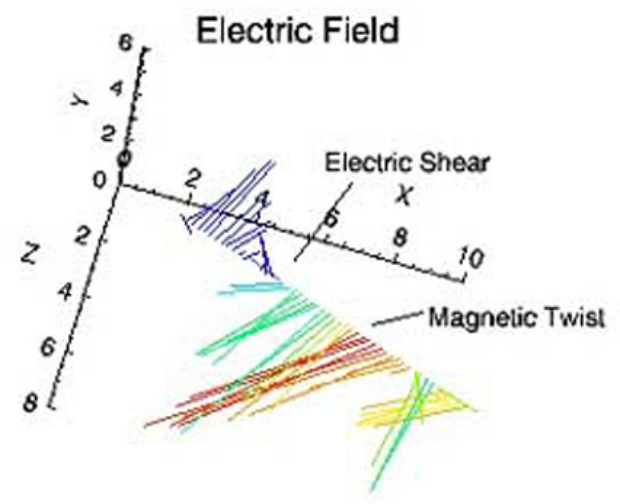

Magnetic Field

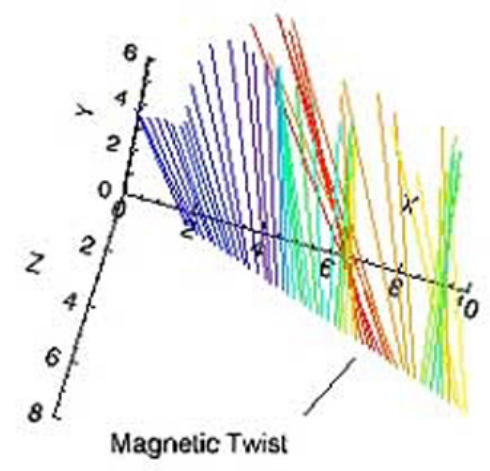

Fig. 20. Top panel: two selected energy channels sensitive to typical magnetospheric electrons ( $2 \mathrm{keV}$, red curve) and cusp/magnetosheath electrons $(44 \mathrm{eV}$, black curve) from the Cluster electron experiment PEACE, plotted in comparison to the total electric (black curve) and magnetic (red curve) field in the central panel. Also in the central panel, the magnetic field component in the direction of the motion of the transient at 13:30 UT is plotted as a shaded red curve. In the bottom two panels, we display the electric (left panel) and magnetic (right panel) vectors as a spatial feature along the trajectory of the moving structure in GSE coordinates $\left(R_{E}\right.$ units) with an arbitrary origin in the vicinity of Cluster at 13:30 UT. The intensity of the field is colour-coded as to overcome projection ambiguities in the 3-D presentation. Two major events are labelled (see text for more details on this figure). rent sheet equatorward of the initial current pair must be due to a response of the coupled ionosphere-magnetosphere system, thereby allowing for considerable return flow on lower latitudes (see even the discussion concerning Cluster electric and magnetic field observations below).

Following Lockwood et al. (2000), one can continue to reason that after propagation into the post-noon sector, the westernmost reconnection pulses should contain lower fluxes of injected particles, as they have been travelling longer and with a higher velocity than the leading events. This general conclusion is in excellent agreement with our observations of at least two encounters of cusp-like particle populations by Cluster, and the indication of two flow-channels and their associated adjacent precipitation as seen by the ESR and the NAL cameras. In all data sets presented above, the second trailing event was less pronounced than the leading one.

Having set the stage for why we believe that at a location of 15:00 MLT Cluster was hit by the eastward propagating features of newly-reconnected flux tube packages, stemming from a pre-noon reconnection site, we can now closely inspect the Cluster observations. First, we can conclude that the CIS data most strongly indicates that a true encounter of the cusp occurred with a total drop out of the trapped high energy ions occurring simultaneously with the arrival of high fluxes of low energy magnetosheath-like ions. The typical energy dispersion of the ions is, however, barely visible in Fig. 15. We note that the arrival of cusp ions at Cluster occurs about $10 \mathrm{~min}$ after the first ground-based indications of ongoing reconnection, which is corresponding roughly to the time quoted by Lockwood et al. (2000) for the unbending of reconnected field lines, and by Lockwood and Davis (1995) for the time span of ongoing cusp expansion after an initial reconnection pulse. The plasma density measured by CIS at this moment is about $50 \%$ of the plasma density observed after the exit into the magnetosheath at 15:00 UT (data not shown here, but such information is easily available from the Cluster quicklook data on the Internet). This is in agreement with similar observations of the exterior cusp and theoretical considerations on the mechanism for cusp plasma population (Cowley, 1981; Fuselier et al., 1991). Another indication for a true cusp encounter is the direction of the observed ion bulk flow. At 13:30 UT, CIS observes a primarily eastward $(150 \mathrm{~km} / \mathrm{s})$ and tailward $(100 \mathrm{~km} / \mathrm{s})$ flow with almost no vertical component (Fig. 15), while after the exit to the magnetosheath, CIS sees a typical ion flow around the magnetospheric obstacle, with weaker eastward, but stronger tailward and stronger northward components (data not shown here).

Perhaps more clearly than the CIS ion data, the Cluster 


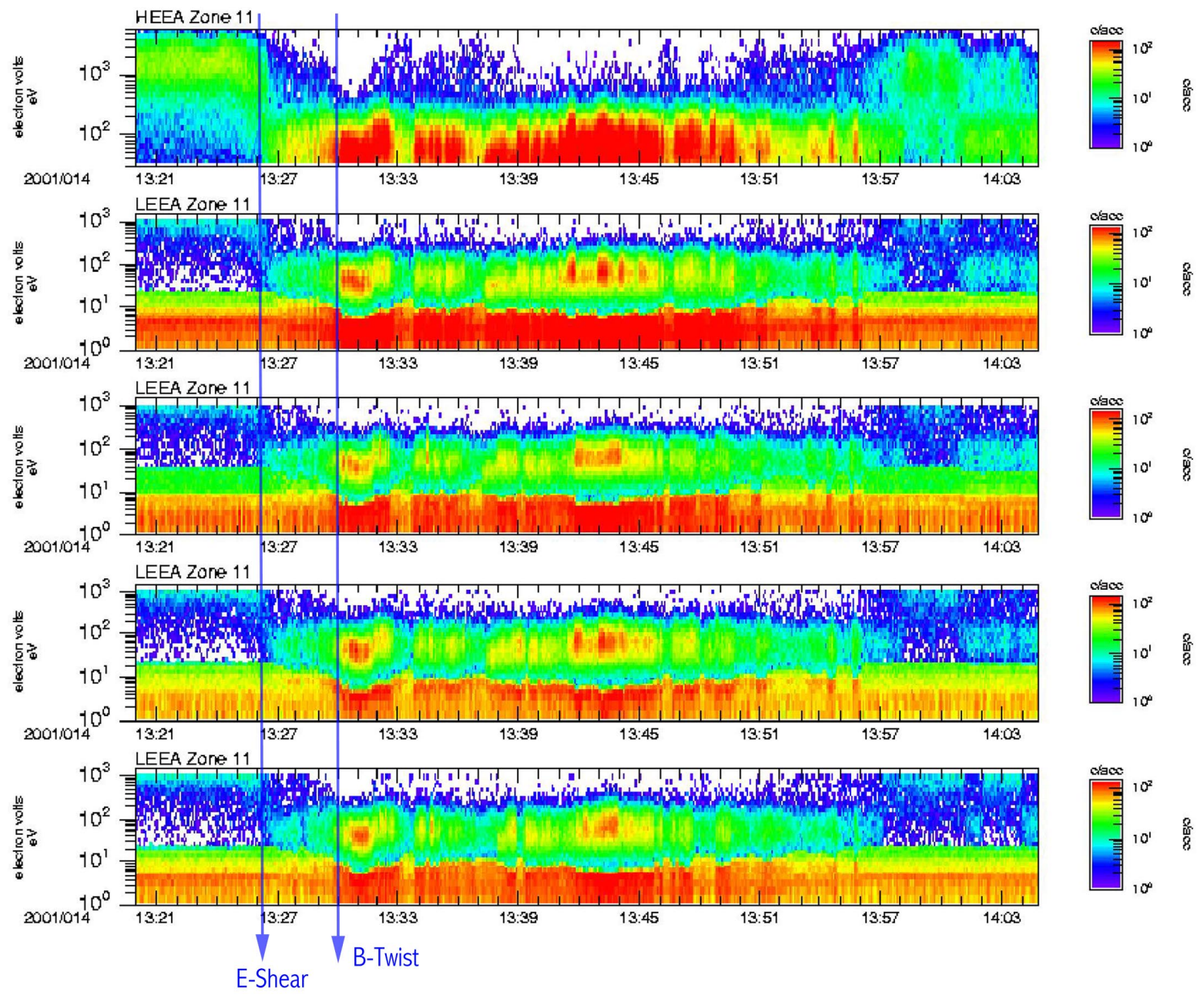

Fig. 21. PEACE data of electron fluxes versus energy and time from the high energy electron detector (HEEA) on one spacecraft and the low energy detectors (LEEA) on all 4 spacecraft from 13:20 to 14:05 UT. The two key events identified in the electric and magnetic field data in Fig. 20 are marked with vertical arrows and labels.

electron data in Fig. 21 show how the trapped high energy electron population is lost in a dispersed way immediately after the onset of reconnection. This occurs simultaneously with the arrival of the first low fluxes of sheath-like electrons. Again, this is in agreement with earlier observations in the vicinity of the active cusp by Burch (1985) and Lockwood and Hapgood (1998). However, as was also pointed out as typical by these authors, the main fluxes of sheath electrons do not arrive from the reconnection site to the west of the spacecraft until the onset of main sheath ion flows is seen in the CIS data. This represents a puzzling and still not fully understood conservation of charge neutrality under such active conditions on newly opened field lines.

The loss of the trapped electron population at field lines connected to Cluster at about 13:26 UT, without immediate low energy electron and ion cusp-like plasma signatures, is additionally confirmed by data from the DMSP F15 satellite, which had a very close conjunction with Cluster between 13:25 and 13:26 UT (see Fig. 2). In Fig. 24, we show the particle spectrograms and ion flow data from the DMSP passage in question. In close agreement with the Cluster observations the electron data of DMSP F15 shows how the satellite first passes the active and highly structured polar cap, a typical feature for northward IMF $B_{Z}$ conditions. At 13:25 UT, it enters a trapped electron population on closed field lines just to the north of the Cluster footprint, only to be overtaken again by the equatorward erosion of the open/closed field line boundary at 13:27 UT. DMSP-F15 enters the closed field line region again, this time only slightly to the south of the Cluster footprint, but not before 13:28 UT . This is unfortunately 2 min too early to observe the arrival of the eastward propagating flow-channel and the cusp particle precipitation seen by Cluster at that time. It is, however, interesting to note that the latitude of the open/closed field line boundary crossed by DMSP-F15 at 13:28 UT is in very good spatial agreement with the observation of the transient flow event seen by the STF radar at 13:30:35 UT (see Fig. 11), and also with the southernmost excursion of the new regime of westward current flow, as seen by the Greenland magnetometers (see central panel of Fig. 9). Thus, the DMSP data confirms inde- 
CLUSTER/STAFF SAMBA 2001/01/14

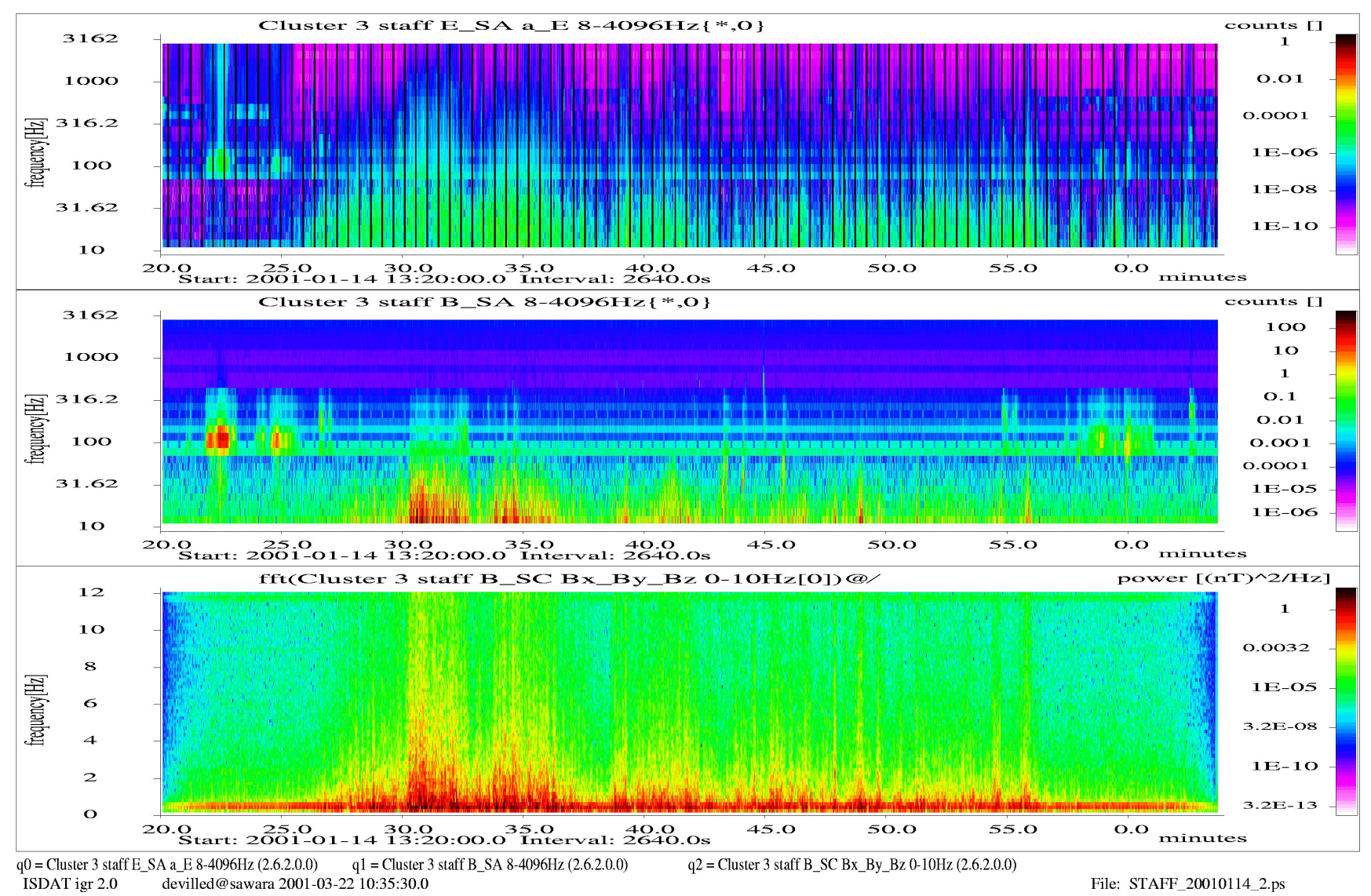

Fig. 22. STAFF spectrograms from 13:20 to 14:00 UT of electric and magnetic field fluctuations in the $8 \mathrm{~Hz}$ to $4 \mathrm{kHz}$ regime (top two panels, respectively) and lower frequency $(0-10 \mathrm{~Hz})$ magnetic fluctuations (bottom panel).

pendently that all discussed transient features seen from the ground as well as from Cluster must indeed occur on newlyopened field lines.

Another puzzling feature in our observations is the temporal behaviour of the electric and magnetic field signatures seen by EFW and FGM (but also in the STAFF wave data). In direct comparison to the DC electric and magnetic field data in Fig. 20 (and Fig. 22 for high frequency variations), one can easily see that the electric field responds much earlier, almost as early as the drop out of the trapped particle population, to the approach of the eastward flow-channel towards Cluster. In the original sketch of Southwood (1987) for a possible ionospheric flow-channel geometry associated with so-called flux-transfer events (FTE), return currents outside the central flow-channel were considered as an essential part of the ionospheric and magnetospheric plasma flow pattern. However, such return flows have later proven to be difficult to observe. Only recently, Pinnock et al. (1993), Rodger and Pinnock (1997), and Thorolfsen et al. (2000) have found clear observational proof of their existence. If one considers that the electric field is closely associated with the plasma flow in the magnetosphere, then the EFW observations can be explained. Centred around 13:30 UT, the electric field transient observed by EFW (Fig. 20) shows a much longer lasting and less sharp feature than the particle signatures of the passing cusp, in very much the same way as the bulk ion velocity transient seen by the CIS instruments (Fig. 15). Fig. 20 (bottom left panel) nicely illustrates how the electric field associated with the approaching new flow-channel (well in advance of the actual encounter with it) is not only enhanced, but sheared by almost $180^{\circ}$, as compared to the pre-existing convection electric field. It appears that a new large-scale, but FTE-like flow pattern is superimposed on the pre-existing convection, thus, affecting the flow and electric field well outside the main flow-channel itself. Similarly, the electric component of the wave measurements (Fig. 22, top panel) reflects the high-frequency fluctuations in the return flow of the approaching central flow-channel.

But why is this early (i.e. distant) response to the approaching flow-channel visible only in the electric and not in the magnetic field observations? We have concluded earlier that the combined ground-based data sets at ionospheric level strongly indicate the presence of two field-aligned current sheets, which imbed the observed transient flow-channel, westward current flow and adjacent particle precipitation. In the ionosphere, such field-aligned current sheets form to- 

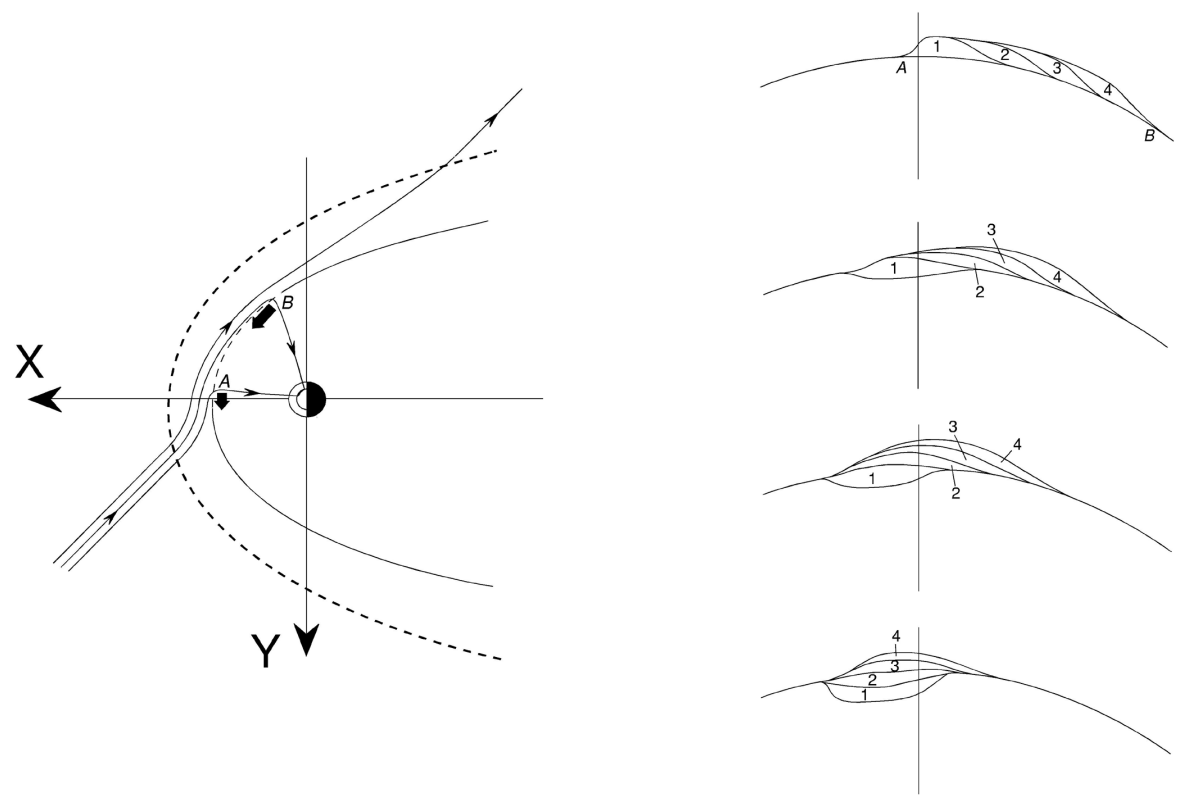

Fig. 23. Left Panel: schematic sketch of the magnetosphere, as viewed from the top. A draped solar wind IMF field line and two newlyreconnected field lines are drawn for a possible reconnection geometry, when the IMF $B_{Y}$ and $B_{X}$ components are both large and negative, while the $B_{Z}$ component is small. Right panel: schematic drawing of the evolution of newly-opened flux, reconnected in successive times, starting at point A (patch 1) and stopping at point B (patch 4).

gether with the ionospheric closure current a toroidal current system where all the magnetic effects are confined to within the three-dimensional current pattern, with the exception of some leakage at the edges. These field-aligned currents must smear out considerably on their way to the exterior cusp at the altitude of Cluster, and cannot be expected to be easily observable. Nevertheless, they must close on the magnetopause and should, therefore, map out to the region encountered by the Cluster spacecraft. In principle, they must also maintain the characteristics of confined magnetic disturbances inside such a closed sheet current circuit. Consequently, we cannot expect Cluster to record any major magnetic effects until the arrival of the field-aligned current sheets that contain the main flow-channel, the cusp particle population and the strongly enhanced magnetic field signature (see Fig. 20, upper panel). The sharpness of the magnetic onset in Fig. 19, striking satellite by satellite in the same sequence as the particle signatures, is another strong argument for the relative confinement of this magnetic disturbance. Finally, the fact that the principal change in the magnetic field direction at 13:30 UT is in the direction of the motion of the transient structure (Fig. 20, right lower panel) supports our earlier conclusion that Cluster is hit from the west (i.e. in basically the GSE $-X$ direction) by the leading edge of the eastward expanding flow-channel. The fact that CIS also does not see any shear in the direction of the gross ion bulk velocity at that moment (Fig. 15, top panel) is another important indicator of a head-on, rather than a sideways collision with the flow-channel.

From the upper panel of Fig. 20, it is clear that the main deviation of $\boldsymbol{B}$ into the $-X$-direction lasts exactly as long as the cusp particle signatures, reflecting the close coupling of both effects via field-aligned currents. We have noted earlier that both magnetic and particle effects hit the spacecraft in the same temporal sequence. Such a sharp magnetic field signature confined within shielding field-aligned current sheets would consequently also be the most plausible explanation for the quite surprising observation of an increase in the total magnetic field during this encounter of the exterior cusp. It should typically decrease during encounters of the exterior cusp proper. We must conclude that our observations probably deal with a rather untypical situation, where strong fieldaligned currents associated with the flow-channel result in a major deformation of the dayside magnetosphere, bringing the cusp plasma from the pre-noon to the post-noon sector. However, at this stage of our understanding of cusp dynamics, we have actually no clear view of how untypical this kind of behaviour actually is. Considering the unique coverage and quality of the data that is now at our disposal, we should prepare ourselves better for the encounter of more unknown, and probably not at all untypical features of cusp dynamics.

The last aspect of this event to be discussed is the fact that we observe no indications of lobe cell reconnection, in spite of the fact that the IMF is clearly northward during most of the studied interval. The data from the network of SuperDARN radars in Fig. 6 show at 13:35 UT a superimposed dayside convection cell in the same direction as the viscous two-cell convection pattern that remains in the contracted polar cap both before and after the main event. In addition the magnetic meridian chain data, the optical auroral images, and the data along the poleward directed individual radar beams show only signatures of poleward moving transients, again a 
F15 14 Jan 2001

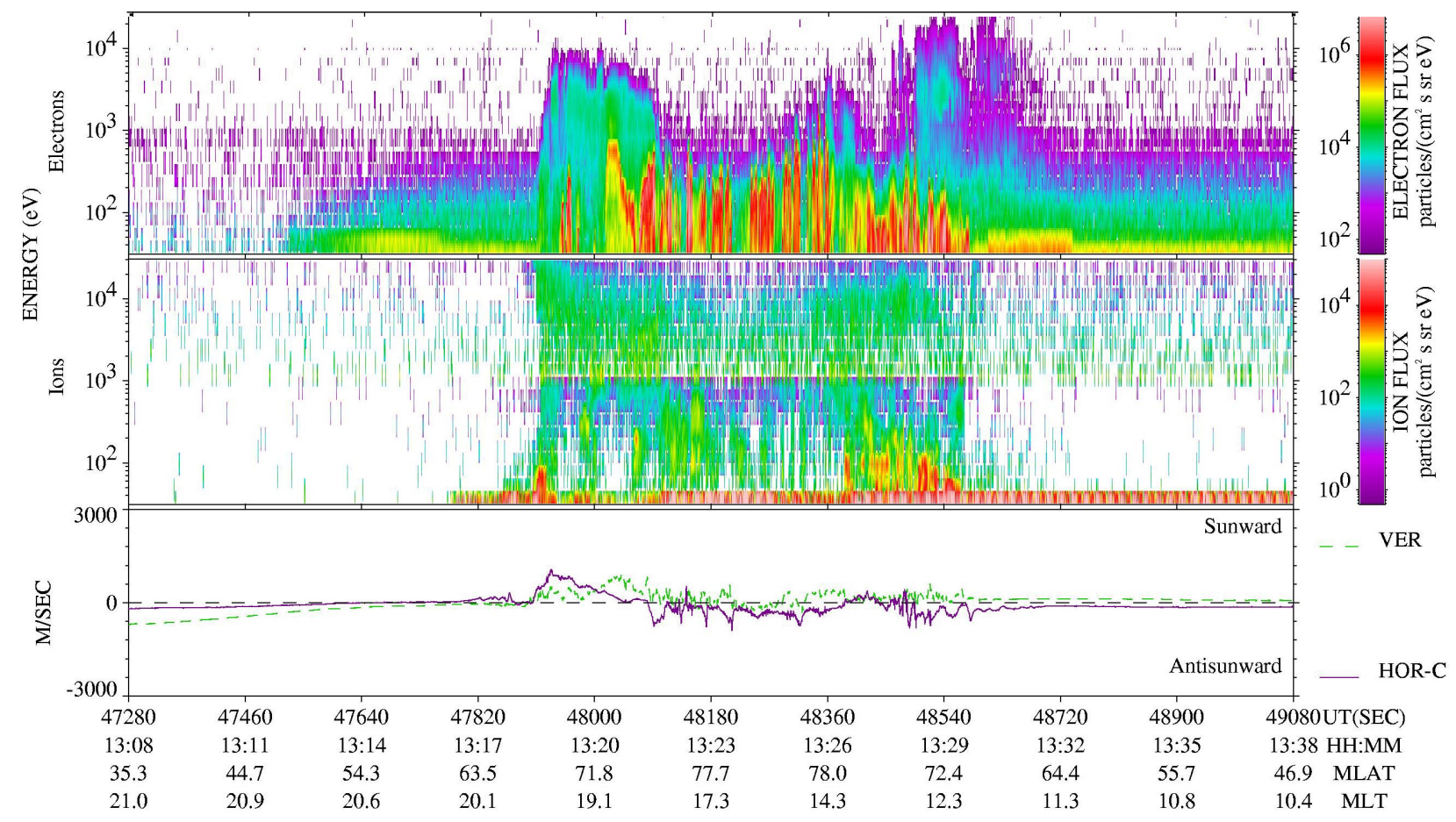

Fig. 24. From top to bottom: electron and ion spectrograms and plasma flow measurements by the DMSP F15 satellite during a passage over Greenland from 13:08 to 13:38 UT on 14 January 2001 (see Fig. 2 for the orbit projection to the ionosphere).

sign for subsolar reconnection, which is typical for southward IMF $B_{Z}$. Previous studies during intervals of large IMF clock angle deviations from the north-south meridian (in other words, IMF directions close to the equatorial plane with small $B_{Z}$ and large $B_{Y}$ ) have shown that features of lobe reconnection and subsolar reconnection can typically coexist, leading to a bifurcation of the cusp auroral features (Sandholt et al., 1996, 1998a, b; Lockwood and Moen, 1999; McCrea et al., 2000). In contrast, we have seen no signs of coexisting sub-solar and lobe-reconnection features. In the case presented here a quite moderate deviation of the IMF clock angle from almost due northward to westward has resulted in a surprisingly large magnetospheric and ionospheric effect, solely caused by subsolar reconnection. The produced flowchannel reached a longitudinal extent of more than $5 \mathrm{~h}$ in local time, transporting cusp plasma from its pre-noon location over into the post-noon sector.

\section{Conclusions}

In this study, a wealth of global ground-based data and the first ever in situ multi-satellite data have been utilised to analyse a relatively unusual magnetospheric topology in a relatively undisturbed solar wind condition. We have shown that even moderate solar wind disturbances can lead to dramatic transient magnetospheric and ionosperic effects, such as the transport of cusp-like plasma and convection features over $5 \mathrm{~h}$ in MLT. Without the global and meso-scale ground- based data (presented in new and more instructive ways), and the well coordinated combination with the first multisatellite data in space it would have been basically impossible to understand the phenomenon presented in this study. Most likely, it would have passed by unstudied or alternatively, it would have been catagorised as "unexplained transient magnetosheath encounters due to some peculiar indention of the magnetopause."

We recall that ever since the early history of Cusp studies there has been a tendency for studies using ground-based data to contribute to the understanding of the Cusp as a transient dynamic feature (e.g. Cowley et al., 1991a), while studies based only on satellite data, often inferred the Cusp as a rather static spatial feature. Combining knowledge from both types of datasets, today also statistical surveys of satellite data (e.g. Newell et al., 1989, and Newell and Meng, 1992) come to conclusions about dynamically growing and shrinking Cusp features, reaching longitudinal extents of more than 2 hours of MLT.

The event study presented here clearly raises a number of additional questions:

- If a moderate change in the IMF conditions during a generally quiet period can have such dramatic effects on the extent and transport of Cusp-like features in the magnetosphere (more than $5 \mathrm{~h}$ in MLT), then what can we expect to happen during really disturbed conditions?

- How can such a strong sub-solar reconnection event oc- 
cur during, according to all that we know, quite unfavourable conditions?

- What is the role and how is the magnetospheric closure of the strong field-aligned currents in this process?

We believe that it is time to prepare ourselves for another revision of our view of the dynamic cusp. A better and hopefully final understanding of cusp dynamics in response to IMF changes can and will only be gained by the combination of data from global ground-based networks and the threedimensional Cluster measurements in space.

Acknowledgements. This paper is dedicated to the memory of three Cluster PIs, Alan Johnstone, Les Wolliscroft and Berend Wilken. Alan, Berend and Les played an important role in the planning phase of the Cluster Ground-Based Initiative. The scientific farsightedness and supportive attitude of all three of them will always be remembered. We thank Prof. R. Bonnet and all members of ESA Councils, Committees, and staff for making the revival of the unique Cluster mission possible. EISCAT is an association of seven member states - France, Germany, Sweden, Norway, Finland, UK and Japan - and we are grateful to the directors and staff of EISCAT for the provision and operation of the research facilities. The SuperDARN radars are supported by funds from the research agencies of Australia, Canada, Finland, France, Italy, Japan, Sweden, UK, and the USA. The MIRACLE network is operated as an international collaboration under the leadership of the Finnish Meteorological Institute. The IMAGE magnetometer network data are collected as a Finnish-German-Norwegian-Polish- Russian-Swedish project. In Sweden EISCAT, SuperDARN, and MIRACLE are funded by the Research Council (VR) and HO, PE, EB, FP, AV and SB acknowledge financial support from VR. MLo, MD, AF, AB, IM, DM, IMcC, GP, MLe, MT, RS, JW, MW and IK in the UK are grateful for support from PPARC; MFM in Italy acknowledges support from PNRA, Italy, and ME an US-NSF grant ATM-0000339. The work by GL at HAO/NCAR was supported by the NASA SEC Guest Investigator program. Work at CESR was funded by CNES grants. We gratefully acknowledge the valuable use of ACE satellite data made available via the WWW by CalTech. In particular we would like to thank all the past and present members of the Working Group for Cluster Ground-Based Coordination (CGBWG) and the Cluster Science Working Team (SWT), who all together made this fantastic coverage of data possible.

The Guest Editor P. Escoubet thanks H. Carlson for his help in evaluating this paper.

\section{References}

André, M., Behlke, R., Wahlund, J.-E., et al.: Multi-spacecraft observations of broadband waves near the lower hybrid frequency at the Earthward edge of the magnetopause, Ann. Geophysicae, this issue, 2001.

Balogh, A., Carr, C. M., Acuña, M. H., et al.: The Cluster magnetic field investigation: overview of in-flight performance and initial results, Ann. Geophysicae, this issue, 2001.

Brace, L. H., Theis, R. F., and Hoegy, W. R.: A global view of the F-region electron density and temperature at solar maximum, Geophys. Res. Lett., 9, 989-992, 1982.

Burch, J. L.: Quasi-neutrality in the polar cusp, Geophys. Res. Lett., 12, 469-472, 1985.
Burch, J. L., Reiff, P. H., Heelis, R. A., Winningham, J. D., Hanson, W. B., Gurgiolo, C., Menietti, J. D., Hoffman, R. A., and Barfield, J. N.: Plasma injection and transport in the mid-altitude polar cusp, Geophys. Res. Lett., 9, 921-924, 1982.

Burch, J. L., Reiff, P. H., Menietti, J. D., Heelis, R. A., Hanson, W. B., Shawhan, S. D, Shelley, E. G., Suguira, M., Weimer, D. R., and Winningham, J. D.: IMF $B_{y}$-dependent plasma flow and Birkeland currents in the dayside magnetosphere, 1. Dynamics Explorer Observations, J. Geophys. Res., 90, 1577-1593, 1985.

Chapman, S. and Ferraro, V. C. A.: A new theory of magnetic storms. Part I. The initial phase, Terr. Mag. Atmos. Elect., 36, 77, 1931

Clauer, C. R., Stauning, P., Rosenberg, T. J., Frus, C. H., Miller, P. M., Sitar, R. J., Papitashvili, V. O., Clauer, C. R., Levitin, A. E., Belov, B. A., Provan, G., Yeoman, T. K., and Cowley, S. W.: Geophys. Res. Lett., 26, 521-524 1995.

Cowley, S. W. H.: Magnetospheric asymmetries associated with the $Y$-component of the IMF, Planet Space Sci., 29, 79, 1981.

Cowley, S. W. H.: The causes of convection in the Earth's magnetosphere: A review of developments during IMS, Rev. Geophys., 20, 531-565, 1982.

Cowley, S. W. H.: Acceleration and heating of space plasmas: basic concepts, Annales Geophysicae, 9, 176, 1991.

Cowley, S. W. H., Freeman, M. P., Lockwood, M., and Smith, M. F.: The ionospheric signature of flux transfer events, in "Cluster - dayside polar cusp”, ESA SP-330, (Ed) Barron, C. I., European Space Agency Publications, Nordvijk, The Netherlands, pp 105112, 1991a.

Cowley, S. W. H., Morelli, J. P., and Lockwood, M.: Dependence of convective flows and particle precipitation in the high-latitude dayside ionosphere on the $X$ and $Y$ components of the interplanetary magnetic field, J. Geophys. Res., 96, 5557-5564, $1991 \mathrm{~b}$.

Crooker N. U., Toffoletto, F. R., and Gussenhoven, M. S.: Opening the cusp, J. Geophys. Res., 96, 3497-3503, 1991.

Curtis, S. A., et al.: DE-2 cusp observations: role of plasma instabilities in topside ionospheric heating and density fluctuations, Geophys. Res. Lett., 9, 997-1000, 1982.

Davis, C. J. and Lockwood, M.: Predicted signatures of pulsed reconnection in ESR data Ann. Geophysicae, 14, 1246-1256, 1996.

Décréau, P., Fergeau, P., Krasnosels'kikh, V., et al.: Early results from the WHISPER instrument on Cluster: an overview, Ann. Geophysicae, this issue, 2001.

de la Beaujardiere O., Newell, P., and Rich, R.: Relationship between Birkeland current regions, particle participation, and electric fields, J. Geophys. Res., 98, 7711-7720, 1993.

Eather, R. H. and Mende, S. B.: Airbourne observations of auroral precipitation patterns, J. Geophys. Res., 76, 1746, 1971.

Escoubet, C. P., Smith, M. F., Fung, S. F., Anderson, P. C., Hoffman, R. A., Basinska, E. M., and Bosqued, J. M.: Staircase ion signature in the polar cusp: a case study, Geophys. Res. Lett., 19, 1735-1738, 1992.

Frank, L. A.: Plasmas in the Earth's polar magnetosphere, J. Geophys. Res., 76, 5202, 1971.

Formisano, V.: HEOS-2 observations of the boundary layer from the magnetopause to the ionosphere, Planet. Space Sci., 28, 245257, 1980.

Fuselier, S. A., Klumpar, D. M., and Shelley, E. G.: Ion reflection and transmission during reconnection at the Earth's subsolar magnetopause, Geophys. Res. Lett., 18, 139-142, 1991.

Fuselier, S. A., Lockwood, M., Onsager, T. G., and Peterson, W. K.: The source population for the cusp and cleft/LLBL for southward 
IMF, Geophys. Res. Lett., 26, 1665-1669, 1999.

Gosling, J. T., Thomsen, M. F., Bame, S. J., Elphic, R. C., and Russell, C. T.: Plasma flow reversals at the dayside magnetopause and the origin of asymmetric polar cap convection, J. Geophys. Res., 95, 8073-8084. 1990a.

Gosling, J. T., Thomsen, M. F., Bame, S. J., Onsager, T. G., and Russell, C. T.: The electron edge of the low-latitude boundary layer during accelerated flow events, Geophys. Res. Lett., 17, 1833-1836, 1990b.

Greenwald, R. A., Baker, K., Ruohoniemi, J. M., Dudeney, J. R., Pinnock, M., Mattinand, N., and Leonard, J. M.: Simultaneous conjugate observations of dynamic variations in high-latitude dayside convection due to changes in IMF $B_{Y}$, J. Geophys. Res., 95, 8057, 1990.

Greenwald, R. A., Baker, K. B., Dudeney, J. R., Pinnock, M., Jones, T. B., Thomas, E. C., Villain, J.-P., Cerisier, J.-C., Senior, C., Hanuise, C., Hunsucker, R. D., Sofko, G., Koehlers, J., Nielsen, E., Pellinen, R., Walker, A. D., Sato, N., and Yamagishi: DARN/SuperDARN: A global view of the dynamics of high-latitude convection, Space Science Reviews, 71, 761-796 1995.

Gustafsson, G., André, M., Eriksson, A. I., et al.: First results of electric field and density observations by Cluster EFW based on initial months of operation, Ann. Geophysicae, this issue, 2001.

Haerendel, G., Paschmann, G., Sckopke, N., Rosenbauer, H., and Hedgecock, P. C.: The frontside boundary layer of the magnetopause and the problem of reconnection, J. Geophys. Res., 83, 3195-3216, 1978.

Hapgood, M. A., Tulunay, Y., Lockwood, M., Bowe, G., and Willis, D. M.: Variability of the interplanetary medium at 1 AU over 24 years: 1963-1986, Planet. Space Sci., 39, 411-423, 1991.

Heikkila, W. I.: The morphology of auroral particle precipitation, Space Res., 12, 1343, 1972.

Heikkila, W. J. and Winningham, J. D.: Penetration of magnetosheath plasma to low altitudes through the dayside magnetospheric cusps, J. Geophys. Res., 76, 883, 1971.

Hill, T. W. and Reiff, P. H.: Evidence of magnetospheric cusp proton acceleration by magnetic merging at the dayside magnetopause, J. Geophys. Res., 82, 3623-3628, 1977.

Hughes, T. J., Creutzberg, F., McDiarmid, D. R., Wallis, D. D., Rostoker, G., Samson, J. C., and Cogger, L. L.: The CANOPUS Ground-Based Auroral Instrument Array in The Satellite Ground-Based Coordination Source Book, (Eds) Opgenoorth, H. and Lockwood, M., ESA-SP1198, ESA Publications, 131-143, 1997.

Kelly, J. D., Heinselman, C. J., Vickrey, J. E., and Vondrak, R. R.: The Sondrestrom radar and accompanying ground-based instrumentation, Space Science Reviews, 71, 797-813 1995.

Lockwood, M.: The location and characteristics of the reconnection X-line deduced from low-altitude satellite and ground-based observations: 1. Theory, J. Geophys. Res., 100, 21 791-21 802, 1995.

Lockwood, M.: The relationship of dayside auroral precipitations to the open-closed separatrix and the pattern of convective flow, J. Geophys. Res., 102, 17 475-17487, 1997a.

Lockwood, M.: Energy and pitch angle dispersions of LLBL/cusp ions seen at middle altitudes: predictions by the open magnetosphere model, Ann. Geophysicae, 15, 1501-1514, $1997 \mathrm{~b}$.

Lockwood, M. and Davis, C. J.: The occurrence probability, width and terracing of cusp precipitation in the topside ionosphere for fully-pulsed reconnection at the dayside magnetopause, J. Geophys. Res., 100, 7627-7640, 1995.
Lockwood, M. and Davis, C. J.: On the longitudinal extent of magnetopause reconnection bursts, Ann. Geophysicae, 14, 865-878, 1996.

Lockwood, M. and Hapgood, M. A.: On the Cause of a Magnetospheric Flux Transfer Event, J. Geophys. Res., 103, 2645326478, 1998.

Lockwood, M. and Moen, J.: Reconfiguration and closure of lobe flux by reconnection during northward IMF: possible evidence for signatures in cusp/cleft auroral emissions, Ann. Geophysicae, 17, 996-1011, 1999.

Lockwood, M. and Smith, M. F.: The variation of reconnection rate at the dayside magnetopause and cusp ion precipitation, J. Geophys. Res., 97, 14, 841-847, 1992.

Lockwood, M. and Smith, M. F.: Comment on "Mapping the dayside ionosphere to the magnetosphere according to particle precipitation characteristics" by Newell and Meng, Geophys. Res. Lett., 20, 1739-1740, 1993.

Lockwood, M., Carlson, H. C., and Sandholt, P. E.: The implications of the altitude of transient $630 \mathrm{~nm}$ dayside auroral emissions, J. Geophys. Res., 98, 15 571-15 587, 1993 a.

Lockwood, M, Denig, W. F., Farmer, A. D., Davda, V. N., Cowley, S. W. H., and Lühr, H.: Ionospheric signatures of pulsed magnetic reconnection at the Earth's magnetopause, Nature, 361, 6411, 424-428, 1993b.

Lockwood, M, Onsager, T. G., Davis, C. J., Smith, M. F., and Denig, W. F.: The characteristics of the magnetopause reconnection $X$-line deduced from low-altitude satellite observations of cusp ions, Geophys. Res. Lett., 21, 2757-2760, 1994.

Lockwood, M., Davis, C. J., Onsager, T. G., and Scudder, J. A.: Modelling signatures of pulsed magnetopause reconnection in cusp ion dispersion signatures seen at middle altitudes, Geophys. Res. Lett., 25, 591-594, 1998.

Lockwood, M., McCrea, I. W., Milan, S. E., Moen, J., Cerisier, J. C., and Thorolfsson, A.: Plasma structure within polewardmoving cusp/cleft auroral transients: EISCAT Svalbard Radar observations and an explanation in terms of large local time extent of events, Ann. Geophysicae, 18, 1027-1042, 2000.

Lockwood, M., Opgenoorth, H., van Eyken, A. P., Fazakerley, A., Bosqued, J.-M., Denig, W., Wild, J., Cully, C., Greenwald, R., Lu, G., Amm, O., Frey, H., Strømme, A., Prikryl, P., Hapgood, M. A., Wild, M. N., Stamper, R., Taylor, M., McCrea, I., Kauristie, K., Pulkkinen, T., Pitout, F., Balogh, A., Dunlop, M., Rème, H., Behlke, R., Hansen, T., Provan, G., Eglitis, P., Morley, S. K., Alcaydé, D., Blelly, P.-L., Moen, J., Donovan, E., Engebretson, M., Lester, M., Waterman, J., and Marcucci, M. F.: Coordinated Cluster, ground-based instrumentation and low-altitude satellite observations of transient poleward-moving events in the ionosphere and in the tail lobe, Ann. Geophysicae, this issue, 2001a.

Lockwood, M., Fazakerley, A., Opgenoorth, H., Moen, J., van Eyken, A. P., Bosqued, J.-M., Lu, G., Eglitis, P., McCrea, I. W., Cully, C., Hapgood, M. A., Wild, M. N., Stamper, R., Taylor, M., Wild, J., Provan, G., Amm, O., Kauristie, K., Pulkkinen, T., Strømme, A., Prikryl, P., Pitout, F., Dunlop, M., Balogh, A., Réme, H., Behlke, R., Denig, W., Hansen, T., Greenwald, R., Morley, S. K., Alcayde, D., Blelly, P.-L., Donovan, E., Engebretson, M., Lester, M., Waterman, J., and Marcucci, M. F.: Coordinated Cluster and ground-based instrument observations of transient changes in the magnetopause boundary layer during northward IMF, Ann. Geophysicae, this issue, $2001 \mathrm{~b}$.

Lu, G., Richmond, A. D., Emery, B. A., and Knipp, D. J.: AMIE Procedure and its application, in The Satellite Ground-Based Co- 
ordination Source Book, (Eds) Opgenoorth, H. and Lockwood, M., ESA-SP1198, ESA Publications, 15-23, 1997.

McCrea, I. W. and Lockwood, M.: Incoherent scatter radars, in The Satellite Ground-Based Coordination Sourcebook, (Eds) Opgenoorth, H. and Lockwood, M., ESA-SP1198, ESA Publications, 239-268, 1997.

McCrea, I. W., Lockwood, M., Moen, J., Pitout, F., Eglitis, P., Aylward, A. D., Cerisier, J.-C., Thorolfssen, A., and Milan, S. E.: ESR and EISCAT observations of the response of the cusp and cleft to IMF orientation changes, Ann. Geophysicae, 18, 10091026, 2000.

Mei, Y., Crooker, N. U., and Siscoe, G. L.: Cusp currents from ionospheric vorticity generated by gasdynamic and merging flow fields at the magnetopause, J. Geophys. Res., 100, 7641-7647, 1995.

Moen, J., Holtet, J. A., Pedersen, A., Lybekk, B., Svenes, K., Oksavik, K., Søraas, F., and André, M.: Cluster boundary layer measurements and optical observations at magnetically conjugate sites, Ann. Geophysicae, this issue, 2001.

Newell, P. T. and Meng, C.-I.: The cusp and the cleft/LLBL: Low altitude identification and statistical local time variation, J. Geophys. Res., 93, 14, 549, 1988.

Newell, P. T. and Meng, C.-I.: Mapping the dayside ionosphere to the magnetosphere according to particle precipitation characteristics, Geophys. Res. Lett., 19, 609-612, 1992.

Newell, P. T., Meng, C.-I., Sibeck, D. G., and Lepping, R.: Some low-altitude cusp dependencies on the interplanetary magnetic field, J. Geophys. Res., 94, 8921-8927, 1989.

Øieroset, M., Sandholt, P. E., Denig, W. F., and Cowley, S. W.: Northward interplanetary magnetic field cusp aurora and high-latitude magnetopause reconnection, J. Geophys. Res., 102, $11349-11362,1997$.

Onsager, T. G., Kletzing, C. A., Austin, J. B., and MacKiernan, H.: Model of magnetosheath plasma in the magnetosphere: cusp and mantle precipitations at low altitudes, Geophys. Res. Lett., 20, 479-482, 1993.

Opgenoorth, H. J. and Lockwood, M.: Opportunities for magnetospheric research with coordinated Cluster and Ground-Based Observations, Space Sci. Rev., 79, 599-637, 1997.

Owen, C. J., Fazakerley, P. J., Carter, P. J., et al.: Cluster PEACE observations of electrons during magnetosphere flux transfer events, Ann. Geophysicae, this issue, 2001.

Paschmann, G., Papamastorakis, I., Baumjohann, W., Sckopke, N., Carlson, C.W., Sonnerup, B.U.Ö., and Lühr, H.: The magnetopause for large magnetic shear: AMPTE/IRM observations, J. Geophys. Res., 91, 11 099-11 115, 1986.

Pilipenko, V. A., Fedorov, E. N., Eneebretson, M. J., Papitashvili, V. O., and Watermann, J. F.: Poleward progressing quasiperiodic disturbances at cusp latitudes: the role of wave processes, J. Geophys. Res., 105, 27 569-27 587, 2000.

Pinnock, M., Rodger, A. S., Dudeney, J. R., Rich, F., and Baker, K. B.: High spatial and temporal resolution observations of the ionospheric cusp, Ann. Geophysicae, 13, 919-925, 1995.

Pinnock, M., Rodger, A. S., Dudeney, J. R., Baker, K. B., Neweli, P. T., Greenwald, R. A., and Greenspan, M. E.: Observations of an enhanced convection channel in the cusp ionosphere, J. Geophys. Res., 98, 3767-3776, 1993.

Reiff, P. H., Hill, T. W., and Burch, J. L.: Solar wind plasma injection at the dayside magnetospheric cusp, J. Geophys. Res., 82, 479-491, 1977.

Rème, H., Aoustin, C., Bosqued, J. M., et al.: First multispacecraft ion measurements in and near the Earth's magnetosphere with the identical Cluster Ion Spectrometry (CIS) experiment, Ann. Geophysicae, this issue, 2001.

Rezeau, L., Sahraoui, F., d'Humières, E., et al.: A case study of low-frequency waves at the magnetopause, Ann. Geophysicae, this issue, 2001.

Richmond, A. D.: Assimilated mapping of ionospheric electrodynamics, Adv. Space Res., 12, 59, 1992.

Rodger, A. S. and Pinnock, M.: The ionospheric response to flux transfer events: the first few minutes, Ann. Geophysicae, 15, 685-691, 1997.

Rodger, A. S., Pinnock, M., Dudeney, J. R., Baker, K. B., and Greenwald, R. A.: A new mechanism for polar patch formation, J. Geophys. Res., 99, 6425-6436, 1994.

Rosenbauer, H., Gruenwaldt, H., Montgomery, M. D., Paschmann, G., and Sckopke, N.: HEOS-2 plasma observations in the distant polar magnetosphere: the plasma mantle, J. Geophys. Res., 80, 2723-2737, 1975.

Ruohoniemi, J. M. and Baker, K. B.: Large-scale imaging of highlatitude convection with Super Dual Auroral Radar Network HF radar observations, J. Geophys. Res., 103, 20 797-20 811, 1998.

Sandford, B. P.: Aurora and airglow intensity variations with time and magnetic activity at southern high-latitudes, J. Atmos. Terr. Phys., 26, 749, 1964.

Sandholt, P. E.: Auroral electrodynamics at the cusp/cleft poleward boundary during northward interplanetary magnetic field, Geophys. Res. Lett., 18, 805-808, 1991.

Sandholt, P. E., Egeland, A., Holtet, J. A., Lybekk, B., Svenes, K., and Asheim, S.: Large- and small-scale dynamics of the polar cusp, J. Geophys. Res., 90, 4407-4414, 1985.

Sandholt, P. E., Lockwood, M., Denig, W. F., Elphic, R. C., and Leontjev, S.: Dynamical auroral structure in the vicinity of the polar cusp: multipoint observations during southward and northward IMF, Ann. Geophysicae, 10, 483-497, 1992.

Sandholt, P. E., Farrugia, C. J., Moen, J., Cowley, S. W., and Lybekk, B.: Dynamics of the aurora and associated convection currents during a cusp bifurcation event, Geophys. Res. Lett., 25, 4313-4316, 1998a.

Sandholt P. E., Farrugia, C. J., Moen, J., and Lybekk, B.: The dayside aurora and its regulation by the interplanetary magnetic field, in Polar cap boundary phenomena, (Eds) Moen, J., Egeland, A., and Lockwood, M., NATO ASI Ser C, Kluwer, Dordrecht, 509, 189-208, 1998b.

Sandholt, P. E., Farrugia, C. J., Oieroset, M., Stauning, P., and Cowley, S. W.: Auroral signature of lobe reconnection, Geophys. Res. Lett., 23, 1725-1728 1996.

Saunders, M. A.: The origin of cusp Birkeland currents, Geophys. Res. Lett., 16, 151-154, 1989.

Smith, M. F. and Lockwood, M.: The Earth's magnetospheric cusps, Rev. Geophys., 34, 2, 233-260, 1996.

Southwood, D. J.: The ionospheric siganture of flux transfer events, J. Geophys. Res., 92, 3207, 1987.

Spreiter, J. R., Summers, A. L., and Alksne, A. Y.: Hydromagnetic flow around the magnetosphere, Planet. Space Sci., 14, 223-253, 1966.

Stasiewicz, K.: Orbit visualization tool, User's Guide, Version 1.1, ESA/ESTEC, 1992.

Stauning, P., Friis-Christensen, E., Rasmussen, O., and Vennerstrøm, S.: Progressing polar convection disturbances: Signature of an open magnetosphere, J. Geophys. Res., 99, 11, 303-11, 317, 1994.

Stauning, P.: Progressing IMF $B_{Y}$-related polar ionospheric convection disturbances, J. Geomag. Geoelectr., 47, 735-757, 1995. 
Stubbs, T. J., Lockwood, M., Cargill, P., Fennel, J., Grande, M., Kellett, B., Perry, C. H., and Rees, A.: Dawn/dusk asymmetry in particles of solar wind origin within the magnetosphere, Ann. Geophysicae, 19, 1-9, 2001.

Syrjäsuo, M., Pulkkinen, T. I., Pellinen, R. P., Janhunen, P., Kauristie, K., Viljanen, A., Opgenoorth, H. J., Karlsson, P., Wallman, S., Eglitis, P., Nielsen, E., and Thomas, C.: Observations of substorm electrodynamics using the MIRACLE network, in Proc. of the 4th International Conference on Substorms, ICS4, Lake Hamana, Japan, Terra Scient. Publ. Comp., Tokyo, Japan, pp. 111-114, 1998.

Taguchi, S., Sugiura, M., Winningham, J. D., and Slavin, J. A.: Characterization of the IMF $B_{Y}$ dependent field-aligned currents in the cleft region based on DE 2 observations, J. Geophys. Res., 98, 1393-1407, 1993.

Thorolfsson, A., Cerisier, J.-C., Lockwood, M., Sandholt, P. E., Senior, C., and Lester, M.: Simultaneous optical and radar signatures of poleward-moving auroral forms, Ann. Geophysicae, 18, 1054-1066, 2000.

Titheridge, J. E.: Ionospheric heating beneath the magnetosphereic cleft, J. Geophys. Res., 81, 1976.

Tsyganenko, N. A.: Modeling the Earth's magnetospheric magnetic field confined within a realistic magnetopause, J. Geophys. Res., 100, 5599-5612, 1995.

Vasyliunas, V. M.: Multiple-branch model of the open magnetopause, Geophys. Res. Lett., 22, 1145-1147, 1995.
Viljanen, A. and Häkkinen, L.: IMAGE magnetometer network, in The Satellite Ground-Based Coordination Source Book, (Eds) Opgenoorth, H. and Lockwood, M., ESA-SP1198, ESA Publications, pp. 111-118, 1997.

Watermann, J., de la Beujardiére, O., Lummerzheim, D., Woch, J., Newell, P. T., Potemra, T. A., Rich, F. J., and Shapshak, M.: The dynamic cusp at low altitudes: a case study utilizing Viking, DMSP-D7, and Sondrestrom incoherent scatter radar observations, Ann. Geophysicae, 12, 1114-1157, 1994.

Wickwar, V. B. and Kofman, W.: Dayside auroras at very highlatitudes: the importance of thermal excitation, Geophys. Res. Lett., 11, 923-926, 1984.

Wilken, B., Daly, P. W., Mall, U., et al.: First results from the RAPID Imaging /Energetic Particle Spectrometer onboard Cluster, Ann. Geophysicae, this issue, 2001.

Woch, J. and Lundin, R.: Magnetosheath plasma precipitation in the polar cusp and its control by the interplanetary magnetic field, J. Geophys. Res., 97, 1421-1430, 1992.

Yeoman, T. K., Milling, D. K., and Orr, D.: Pi2 pulsation polarization patterns on the UK sub-auroral magnetometer network (SAMNET), Planetary and Space Science, 38, 589-602, 1990.

Yeoman, T. K., Lester, M., Cowley, S. W. H., Milan, S. E., Moen, J., and Sandholt, P. E.: Simultaneous observations of the cusp in optical, DMSP, and HF radar data, Geophys. Res. Lett., 24, 2251-2254, 1997. 